\title{
Molecular Structure, Vibrational Spectra, Quantum Chemical Calculations and Photochemistry of Picolinamide and Isonicotinamide Isolated in Cryogenic Inert Matrixes and in the Neat Low-Temperature Solid Phases
}

\author{
Ana Borba, ${ }^{\dagger}$ Andrea Gómez-Zavaglia, ${ }^{\dagger, *}$ and R. Fausto $*, \dagger$ \\ Department of Chemistry, University of Coimbra, P-3004-535, Portugal, and Facultad de Farmacia y \\ Bioquímica, Universidad de Buenos Aires, RA-1113, Argentina
}

Received: August 15, 2007; In Final Form: October 14, 2007

\begin{abstract}
Picolinamide (PA) and isonicotinamide (INA), two structural isomers of pyridinecarboxamide, have been investigated by matrix isolation and low-temperature solid-state infrared spectroscopy, combined with UV ( $\lambda$ $>235 \mathrm{~nm}$ ) photoexcitation and density functional theory and ab initio (MP2) theoretical studies. In consonance with the theoretical data, both PA and INA were found to exist in a single conformation in cryogenic rare gas matrixes. Comparison between the experimental spectra of the matrix-isolated compounds with those theoretically predicted allowed for full assignment of the experimental spectra. In situ UV $(\lambda>235 \mathrm{~nm})$ irradiation of the matrixes showed that only PA reacts, with production of isocyanic acid and pyridine, the first photoproduct further reacting to yield $\mathrm{CO}+\mathrm{NH}$ and cyanic acid. The different photochemical behavior of the two compounds was explained taking into consideration their different structures. The infrared spectra of (i) the low-temperature glassy state resulting from fast deposition of vapors of the compounds onto a substrate cooled to $10 \mathrm{~K}$, (ii) the crystal resulting from the annealed amorphous film of the compound, and (iii) the room-temperature crystals ( $\alpha$-phase) of the studied compounds were also obtained, fully assigned and correlated with intermolecular interactions present in the condensed phases, in particular H-bond interactions, showing that these latter are stronger in INA than in PA.
\end{abstract}

\section{Introduction}

Picolinamide (PA; 2-pyridinecarboxamide) and isonicotinamide (INA; 4-pyridinecarboxamide) are pyridine derivatives bearing the carboxamide group at the $\beta$ and $\gamma$ positions, respectively (Scheme 1).

Both compounds show important biological activity. ${ }^{1-6} \mathrm{PA}$ was found to be a strong inhibitor of poly(ADP-ribose) synthetase, ${ }^{7}$ while INA has been shown to possess strong antitubercular, antipyretic, fibrinolytic, and antibacterial properties. ${ }^{8}$ Because of their strong pharmacological effects, mixed salts of INA find extensive use as drugs in various biological and medicinal processes. ${ }^{8}$

In both PA and INA, the pyridyl ring is structurally rigid, but the carboxamide moiety can in principle adopt different rotameric structures. ${ }^{9,13}$ An important aspect of the amide linkage is its partial double bond character that results from donation of lone-pair electron density from the amide nitrogen to the carbonyl group. This leads to a significantly higher barrier to $\mathrm{C}-\mathrm{N}$ amide bond rotation than those found in amines and, in general, also to planarization of the molecule around the amide nitrogen atom. ${ }^{14}$ In the two compounds considered in the present study, the degree of $\pi$ electron donation within the amide group can be expected to be affected to some extent by electronic effects due to the pyridyl ring. Other direct interactions between the $-\mathrm{NH}_{2}$ amide group and the pyridyl moiety shall also take place, such as electrostatic and steric interactions. All these interactions can be expected to be different in PA and INA,

* Corresponding author. E-mail: rfausto@ci.uc.pt.

University of Coimbra.

$\doteqdot$ Universidad de Buenos Aires.

\section{SCHEME 1: Picolinamide (PA) and Isonicotinamide} (INA)

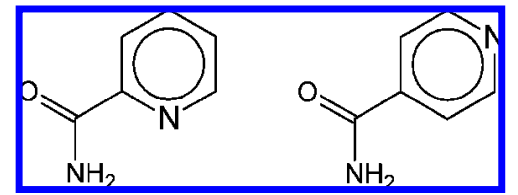

due to the different location of the ring nitrogen atom in the two compounds relative to the amide group.

To the best of our knowledge, the molecular structure of PA has not been investigated experimentally in the gaseous phase. In solution [in $\mathrm{CDCl}_{3}, \mathrm{CD}_{3} \mathrm{CN}$, and $\left(\mathrm{CD}_{3}\right)_{2} \mathrm{CO}$ ], $\mathrm{PA}$ was studied by ${ }^{1} \mathrm{H}$ NMR by Sathyanarayana and co-workers,,${ }^{9,10}$ who have suggested, on the basis of the observed chemical shifts of the amide protons, that the molecule should be planar and bear an intramolecular hydrogen bond between the $-\mathrm{NH}_{2}$ amide group and the pyridyl nitrogen atom. No evidence of any additional conformational state was found in those studies. ${ }^{9,10}$ Further ${ }^{1} \mathrm{H}$ NMR analysis of PA, complemented with ab initio and DFT molecular orbital calculations, has been undertaken by Olsen et al., ${ }^{11}$ who focused their attention particularly to the amide rotational barrier in this compound in comparison with nicotinamide (NA; 3-pyridinecarboxamide). They concluded that the average amide rotational barrier of PA in nitrobenzene and pyridine solutions amounts to ca. $76 \mathrm{~kJ} \mathrm{~mol}^{-1}\left(\Delta H^{\#}\right),{ }^{11}$ which is higher than the corresponding barrier in NA $\left(\Delta H^{\#} \approx 54 \mathrm{~kJ}\right.$ $\left.\mathrm{mol}^{-111}\right)$, mainly due to the presence in PA of the abovementioned intramolecular $\mathrm{H}$-bond between the amide group and the pyridyl nitrogen atom. More recently, Leskowitz et al. ${ }^{12}$ performed similar studies on INA and found that the amide rotational barrier in this compound lies between those of PA 
and NA $\left(\Delta H^{\#} \approx 59 \mathrm{~kJ} \mathrm{~mol}^{-112}\right)$. In their study, Leskowitz et al. presented an analysis of the relative importance of steric, electronic, and $\mathrm{H}$-bonding effects in the three regioisomers (PA, INA, and NA) in relation with the amide internal rotation. The slightly higher amide rotational barrier in INA, compared to that of NA, was attributed by Leskowitz et al. to the more efficient stabilization of the transition states for the amide internal rotation (which were calculated to have the nitrogen atom pyramidalized ${ }^{12}$ ) in NA, compared to the other two compounds.

As for PA, the molecular structure of INA has not been studied experimentally in the gaseous phase. Theoretical studies on this molecule have been reported by Yurdakul et al., ${ }^{8}$ Leskowitz et al., ${ }^{12}$ Bakiler et al., ${ }^{13}$ Filho et al. ${ }^{14}$ and Akyuz et al. ${ }^{15}$ (PA was also considered in ref 13 ).

Solid-state structural studies have been reported for both PA and INA. ${ }^{16,17}$ According to X-ray crystallographic analysis, ${ }^{16}$ PA crystallizes in two modifications, both belonging to the monoclinic space group $P 2{ }_{1} / a$, with four molecules in the unit cell. In one modification ( $\alpha$ phase; $a=16.42, b=7.11, c=$ $5.19 \AA, \beta=100.2^{\circ}$ ), two PA molecules are joined together by a pair of $\mathrm{NH} \cdots \mathrm{O}$ hydrogen bonds to form a dimer, and such dimers are linked by a second set of $\mathrm{NH} \cdots \mathrm{O}$ hydrogen bonds to make endless chains that are parallel to each other; in this modification, the ring does not contribute to hydrogen bonding and the adjacent chains are held together by van der Waals forces. ${ }^{16}$ The second crystalline modification of PA ( $\beta$ phase; $\left.a=20.04, b=11.32, c=5.36 \AA, \beta=98.6^{\circ}\right)$ exhibits a dimeric structure similar to that of the first one, but in this case the lateral linkage of the dimers involves the participation of an atom of the pyridine ring as H-bond acceptor. ${ }^{16}$ In both crystalline modifications, the carboxamide group was found to be planar, with the angle between the pyridine and carboxamide moieties being equal to $19^{\circ}$ in the first crystalline modification ${ }^{16}$ (to the best of our knowledge, no data for this structural parameter in the second crystalline modification has been reported hitherto).

INA does also exhibit polymorphism. ${ }^{17}$ Upon recrystallization from nitrobenzene or nitromethane, one crystalline variety is obtained ( $\alpha$, rodlike crystals), while recrystallization from other solvents, such as ethanol, water, or tetrahydrofuran, produces a second modification ( $\beta$, platelike crystals). Both crystalline varieties are monoclinic, space group $P 2_{1} / c$, with four molecules per unit cell, the cell parameters being $(a=10.176, b=5.732$, $c=23.008 \AA, \beta=98.04^{\circ}$; one molecule in the asymmetric unit) and ( $a=15.735, b=7.998, c=9.885 \AA$, $\beta=105.59^{\circ}$; two molecules in the asymmetric unit), respectively, for rodlike and platelike crystals. In the two crystals, the INA molecules exhibit their amide group slightly twisted out of the plane of the aromatic ring $\left(30.5^{\circ}\right.$ in crystal $\alpha$ and 25.4 and $24.0^{\circ}$ in crystal $\beta) .{ }^{17}$ In crystal $\alpha$, INA dimers are formed and connected into an infinite assembly through symmetry-related $\mathrm{NH} \cdots \mathrm{O}$ hydrogen bonds aligned perpendicularly to the long axis of the dimers. As for one of the PA crystalline modifications, ${ }^{16}$ in this crystalline variety of INA there are no hydrogen bond interactions involving the pyridine ring, neighboring chains being kept together by van der Waals forces. ${ }^{17}$ In crystal $\beta$, the head-tohead dimeric motif is replaced by the $\mathrm{NH}$ (amide) $\cdots \mathrm{N}$ (pyridine) head-to-tail interaction and a catameric $\mathrm{NH} \cdots \mathrm{O}$ hydrogen bond, with the direction of the catamer being almost perpendicular to the chain generated by the amide...pyridine interaction (each asymmetric molecule gives rise to an independent assembly but with identical hydrogen bond connectivity). ${ }^{17}$ Both crystalline
INA modifications are stable for years under normal pressure and temperature conditions. ${ }^{17}$

From a vibrational point of view, both PA and INA have been studied previously in the solid state and adsorbed to surfaces..$^{8,13-15,18-20}$ Surface enhanced Raman spectroscopy (SERS) has been proposed ${ }^{20}$ as a useful tool for quantitative determination of PA and INA (and also NA) in very low concentrations (ppm level). The vibrational spectra of the polycrystalline compounds (noncharacterized crystal modifications) in $\mathrm{KBr}$ pellets at room temperature have been tentatively interpreted with the help of theoretical calculations performed on the isolated molecules at different levels of theory. ${ }^{13-15,18}$ Gas-phase IR spectrum of PA is available at the National Institute of Standards and Technology of the United States (NIST) vapor-phase IR spectra library ${ }^{21}$ and was tentatively assigned in ref 13 .

To the best of our knowledge, there is no data on the photochemistry of either PA or INA. Nevertheless, it has been shown that the analogous compound pyrazinamide, which induces photosensitization in humans causing photohemolysis in erythrocites, ${ }^{22}$ undergoes photolysis (at $\lambda=337 \mathrm{~nm}$ ) through $\alpha$-cleavage between the excited carbonyl of the amide group and the aromatic ring and formation of the pyrazine radical. In aqueous or methanolic solution, this primary photoprocess is followed by hydrogen abstraction and dimerization (and also methanol addition). ${ }^{23}$ A second photolytic pathway was also proposed involving cleavage of the amide bond, followed by a reaction with the solvent to form pyrazine carboxylic acid. ${ }^{24,25}$

In the present investigation, we studied the molecular structure, infrared spectra, and UV-induced $(\lambda>235 \mathrm{~nm})$ photochemistry of PA and INA molecules isolated in cryogenic inert matrixes. The interpretation of the experimental results is supported by theoretical calculations undertaken at both density functional theory (DFT), using the hybrid B3LYP functional, and $a b$ initio second-order Moller-Plesset (MP2) levels of theory. In addition, the IR spectra of the low-temperature (10$280 \mathrm{~K}$ ) solid phases of the two compounds have also been investigated.

\section{Experimental and Computational Methods}

Picolinamide and isonicotinamide were obtained from Aldrich (purity 98 and 99\%, respectively). The matrixes were prepared by co-deposition of the isolating gas (argon, 99.99990\% and xenon, 99.995\%, both obtained from Air Liquide) and the compound under study onto the cooled (10 K for argon; $20 \mathrm{~K}$ for xenon) CsI substrate of the cryostat (APD Cryogenics closecycle helium refrigeration system with a DE-202A expander). A glass vacuum system and standard manometric procedures were used to deposit the isolating gas. PA was placed in a specially designed doubly thermostable Knudsen cell with shutoff possibility whose main component is a NUPRO (SS 4BMRG) needle valve. The temperature of the cell could be controlled separately in the valve nozzle and the sample compartment, enabling a more precise control of the saturated gas pressure over the liquid compound and a better metering function of the valve. In all experiments, the valve nozzle temperature was ca. $323 \mathrm{~K}$. INA was placed in a specially designed temperature-variable mini-oven assembled inside the cryostat. The temperature of the mini-oven used to evaporate INA was, in all experiments, ca. $313 \mathrm{~K}$. The solid films of the neat compounds were prepared in a way similar to that used to obtain the matrixes, but in this case only vapors of the compounds were deposited onto the CsI substrate of the cryostat.

In the annealing experiments, the temperature was controlled and measured by a diode temperature sensor connected to a 
TABLE 1: Total $(E)$ and Relative $(\Delta E)$ Energies (Including Zero-Point Vibrational Contributions) for PA and INA Relevant Forms ${ }^{a}$

\begin{tabular}{lccccc}
\hline & \multicolumn{2}{c}{$\mathrm{B} 3 \mathrm{LYP} / 6-311++\mathrm{G}(\mathrm{d}, \mathrm{p})$} & & \multicolumn{2}{c}{$\mathrm{MP} 2 / 6-31 \mathrm{G}(\mathrm{d}, \mathrm{p})^{b}$} \\
molecule/conformer & $\mathrm{E}$ & $\Delta E$ & & $\mathrm{E}$ & $\Delta E$ \\
\hline PA & -1094842.8 & & -1091350.0 & \\
I & -1094816.6 & & -1091325.5 &
\end{tabular}

${ }^{a}$ Energies in $\mathrm{kJ} \mathrm{mol}^{-1}$; conformers are depicted in Figure 1. ${ }^{b} \mathrm{MP} 2$ energies were corrected by zero-point energies obtained at the B3LYP/ $6-311++\mathrm{G}(\mathrm{d}, \mathrm{p})$ level of theory.

Scientific Instruments digital temperature controller (model $9659)$ to within $\pm 1 \mathrm{~K}$. The temperature variation during the annealing was done in steps of $2 \mathrm{~K}$, in the matrix isolation experiments, and $10-20 \mathrm{~K}$, in the studies on the neat solid compounds.

The IR spectra were collected, with $0.5 \mathrm{~cm}^{-1}$ spectral resolution, on a Mattson (Infinity 60AR Series) Fourier transform infrared spectrometer, equipped with a deuterated triglycine sulfate (DTGS) detector and a $\mathrm{Ge} / \mathrm{KBr}$ beam splitter. To accommodate the cryostat head and allow efficient purging of the instrument by a stream of dry $\mathrm{N}_{2}$ to remove water and $\mathrm{CO}_{2}$ vapors, necessary modifications of the sample compartment of the spectrometer were made.

In situ UV $(\lambda>235 \mathrm{~nm} ; 200 \mathrm{~W})$ irradiation of the matrixes was carried out through the outer $\mathrm{KBr}$ window of the cryostat using a $500 \mathrm{~W} \mathrm{Hg}(\mathrm{Xe})$ lamp (Newport, Oriel Instruments).

The quantum chemical calculations were performed with the Gaussian 98 suite of programs ${ }^{26}$ at the DFT and MP2 levels of theory, using the $6-311++\mathrm{G}(\mathrm{d}, \mathrm{p})$ and $6-31 \mathrm{G}(\mathrm{d}, \mathrm{p})$ basis sets, respectively. ${ }^{27}$ The DFT calculations were carried out with the three-parameter hybrid density functional abbreviated as B3LYP, which includes Becke's gradient exchange correction ${ }^{28}$ and the Lee, Yang, and Parr ${ }^{29}$ and Vosko, Wilk, and Nusair correlation functionals. ${ }^{30}$ Compared with the present DFT calculations, the previously reported ${ }^{13}$ DFT/B3LYP study on PA and INA used the smaller $6-31++G(d, p)$ smaller basis set. Due to its increased flexibility in describing the valence shell, the $6-311++G(d, p)$ basis set appears as a more reliable option, particularly for a correct description of the vibrational modes. Regarding geometries and energies, both basis sets were found to provide similar results.

Structures were optimized using the geometry direct inversion of the invariant subspace method. ${ }^{31}$ Vibrational frequencies were then calculated at each level of theory, and the nature of the stationary points on the potential energy surface resulting from optimization was determined by inspection of the corresponding calculated Hessian matrix. The optimized structures of all conformers described in this study were confirmed to correspond to true minimum energy conformations on the corresponding PES. The calculated frequencies were scaled down by a single factor (0.978) to correct them mainly for the effects of basis set limitations, neglected part of electron correlation, and anharmonicity effects, and used to assist the analysis of the experimental spectra. Normal coordinate analyses were undertaken in the internal coordinates space as described by Schachtschneider, ${ }^{32}$ using the program BALGA and the optimized geometries and harmonic force constants resulting from the DFT(B3LYP)/6-311++G(d,p) calculations. Potential energy profiles for internal rotation were calculated performing a relaxed scan on the PES along the relevant reaction coordinates, and the transition-state structures for conformational intercon-

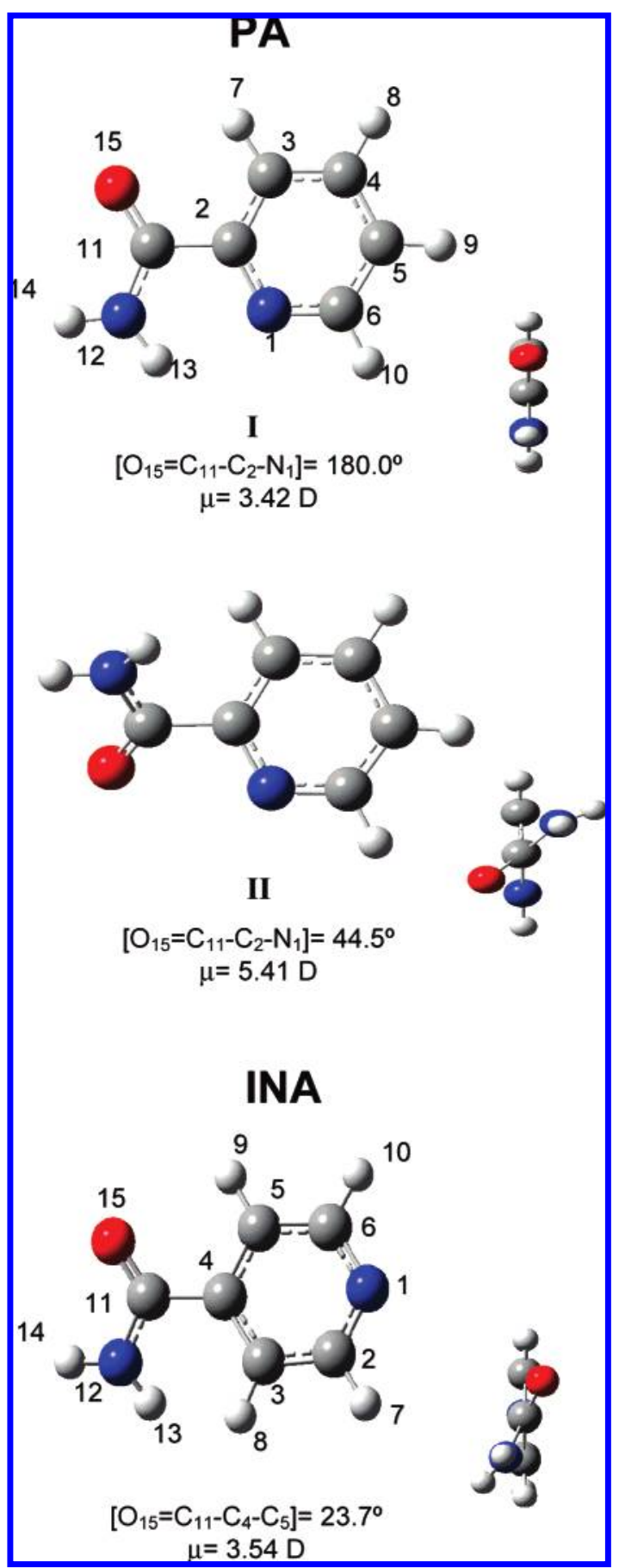

Figure 1. DFT calculated structures for the different conformers of PA and INA, with atom numbering scheme (two perspectives are shown). The DFT calculated twisting angle between the aromatic ring and the carboxamide group is provided, together with the calculated dipole moments (DFT).

version obtained using the synchronous transit-guided quasiNewton method. ${ }^{33}$

\section{Results and Discussion}

Geometries and Energies. The conformationally relevant internal rotational axis in both PA and INA is defined by the $\mathrm{O}_{15}=\mathrm{C}_{11}-\mathrm{C}_{2-} \mathrm{N}_{1}$ dihedral angle. Table 1 displays the calculated relative energies (including zero-point energy corrections) of the conformers, obtained at both the B3LYP/6-311++G(d,p) and MP2/6-31G(d,p) levels of theory. The optimized geometrical parameters for all the structures are provided as Supporting Information (SI) Tables S1 and S2. 


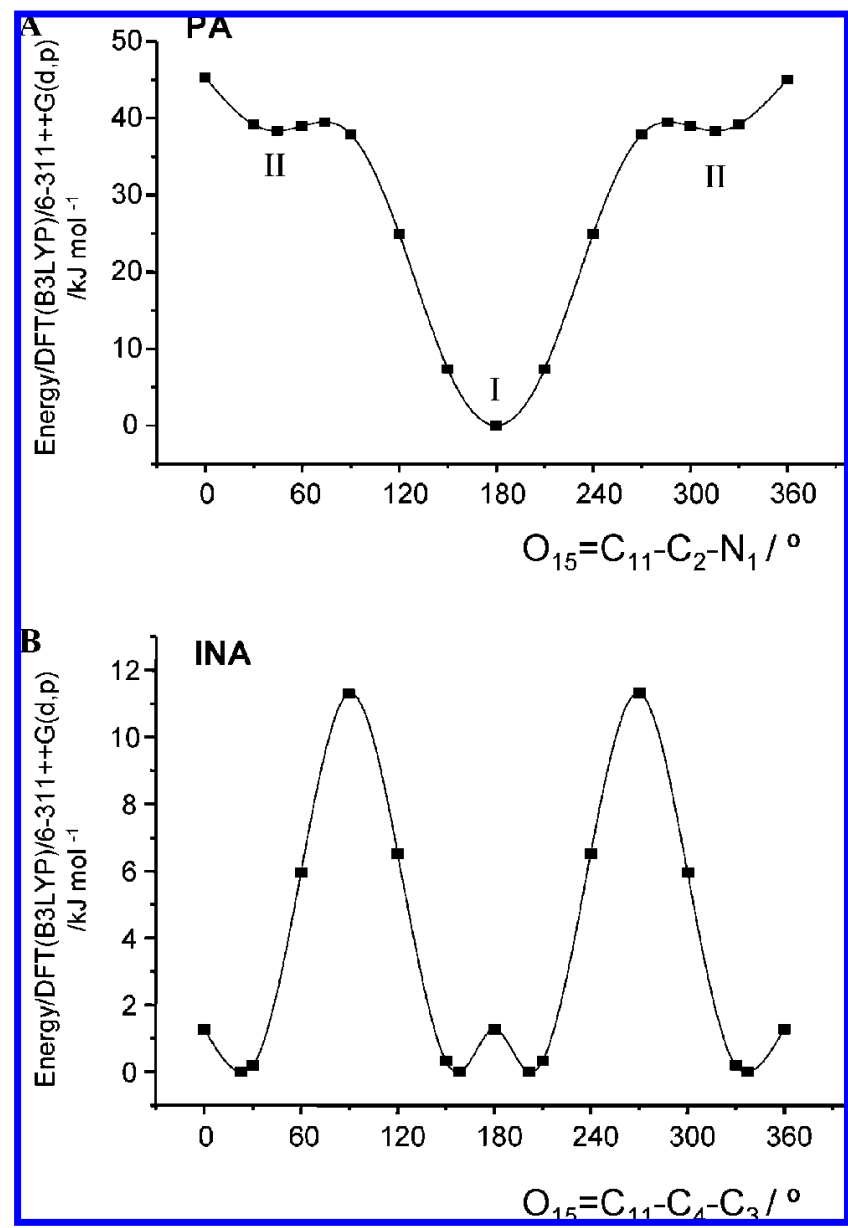

Figure 2. DFT calculated potential energy profiles for internal rotation around the $\mathrm{C}-\mathrm{C}$ bond connecting the carboxamide group to the pyridine ring in picolinamine (A) and isonicotinamide (B).

In agreement with a previous report, ${ }^{13}$ after a systematic investigation of the potential energy surface of PA at the DFT(B3LYP)/6-311++G(d,p) level of calculation, two different minimum energy conformations were found (Figure 1). The most stable form (conformer I) was predicted to be planar, belonging to the $C_{s}$ point group and having the two nitrogen atoms in the syn periplanar geometry. This conformer is stabilized by the presence of two intramolecular hydrogen bondtype interactions $\left(\mathrm{N}_{12} \mathrm{H}_{13} \cdots \mathrm{N}_{1}\right.$ and $\left.\mathrm{C}_{11}=\mathrm{O}_{15} \cdots \mathrm{H}_{7}\right)$ and was predicted by the DFT calculations to be more stable than the second conformer (conformer II) by $37.1 \mathrm{~kJ} \mathrm{~mol}^{-1}(35.7 \mathrm{~kJ}$ $\mathrm{mol}^{-1}$ at the MP2/6-31G(d,p) level). Conformer II is symmetrydegenerated (two equivalent forms) and belongs to the $C_{1}$ point group, with the $\mathrm{O}_{15}=\mathrm{C}_{11}-\mathrm{C}_{2}-\mathrm{N}_{1}$ dihedral angle equal to $\pm 44.5^{\circ}$ $\left( \pm 39.4^{\circ}\right.$, at the MP2 level) and the amide nitrogen atom pyramidalized (the $\mathrm{H}-\mathrm{N}(-\mathrm{C})-\mathrm{H}$ dihedral angle is calculated to be 153.1 and $142.8^{\circ}$, at DFT and MP2 levels of theory, respectively).

The higher stability of conformer I is mainly due to the presence of the intramolecular hydrogen bonds established between $\mathrm{N}_{12}-\mathrm{H}_{13}$ and $\mathrm{N}_{1}$ (H-bond distance: $2.26 \mathrm{pm}$ ) and between $\mathrm{C}_{11}=\mathrm{O}_{15}$ and $\mathrm{H}_{7}(2.51 \mathrm{pm})$. These two H-bonds stabilize the structure and force it to remain planar. In contrast, conformer II is nonplanar mainly due to the repulsion between the $\mathrm{O}_{15}$ and $\mathrm{N}_{1}$ lone pairs and between $\mathrm{H}_{13}$ and $\mathrm{H}_{7}$ (Figure 1).

The rotational barrier separating conformer II from the conformational ground state was predicted by the DFT calculations as being only $1.2 \mathrm{~kJ} \mathrm{~mol}^{-1}$ (Figure 2A). Such a low barrier is an additional factor leading to the practical unimportance of

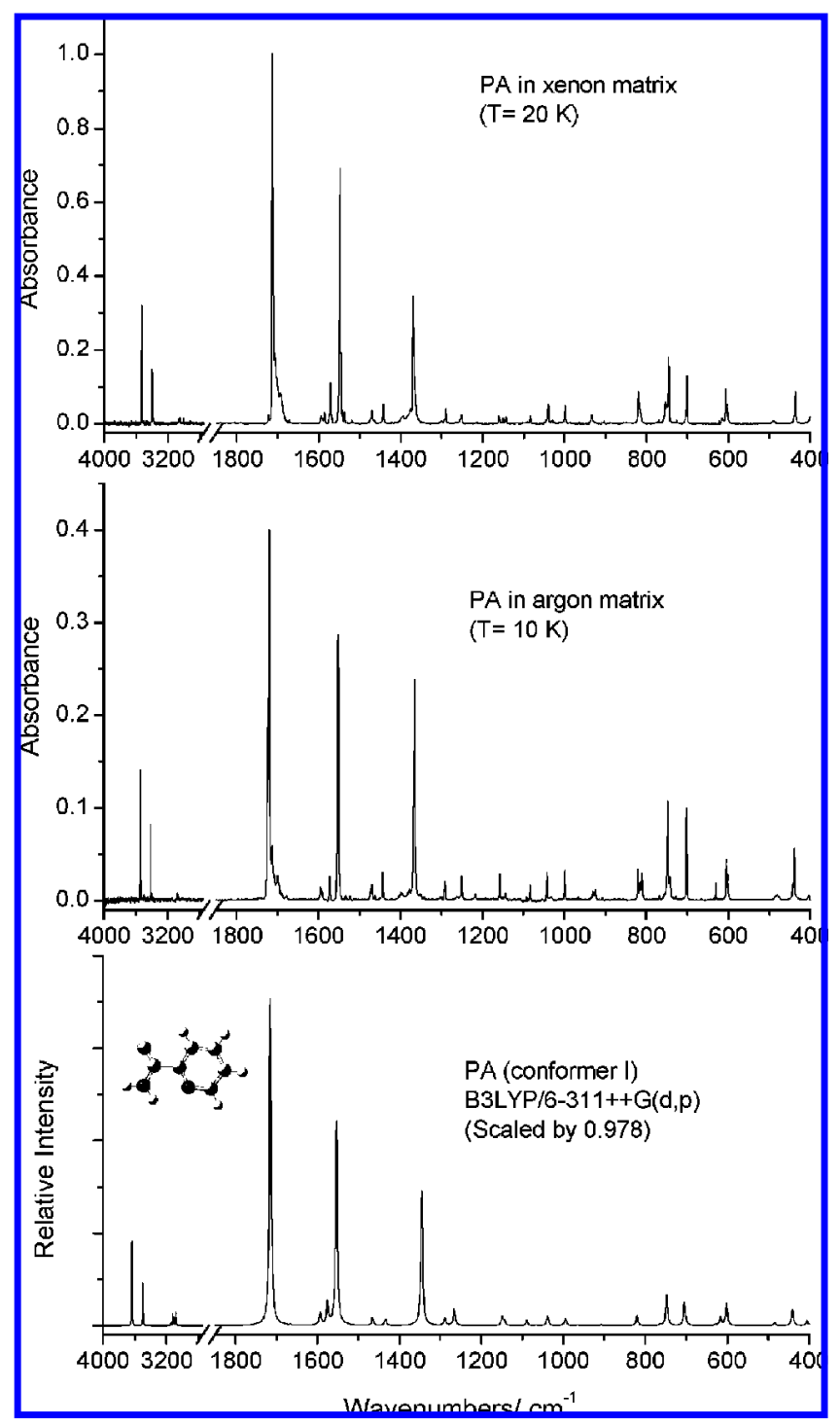

Figure 3. Infrared spectra of PA trapped in argon and xenon matrixes obtained immediately after deposition at 10 and $20 \mathrm{~K}$, respectively, and DFT(B3LYP)/6-311++G(d,p) calculated spectrum (scaled by 0.978) for the most stable conformer (I) of the compound.

the highest energy conformer, since even if this form could be produced in any way it would rapidly convert to the most stable form. Energy barriers of this size have been shown to be easily accessible even during deposition of cryogenic matrixes onto cold substrates kept at a temperature of less than $10 \mathrm{~K}^{34-37}$

In the case of the INA, the carboxamide substituent is in the $\gamma$ position of the pyridine ring. For this reason, the pyridinic nitrogen is too far from the carboxamide group and there is no possibility to be involved in any hydrogen bond. On the other hand, in the planar conformation, $\mathrm{H}_{13}$ would be in close contact to one of the $\beta$-hydrogen atoms of the aromatic ring $\left(\mathrm{H}_{8}\right.$ or $\mathrm{H}_{9}$; Figure 1), thus forcing the molecule to adopt a nonplanar geometry. In turn, the lack of planarity increases the distance between the carbonyl oxygen and the other $\beta$-hydrogen atom $\left(\mathrm{H}_{9}\right.$ or $\left.\mathrm{H}_{8}\right)$, reducing the importance of the $\mathrm{H}$-bond-like interaction between these atoms in comparison to what succeeds in PA. Accordingly, the relevant $\mathrm{C}=\mathrm{O} \cdots \mathrm{H}$ distances in INA and PA are predicted by the DFT calculations to be 2.55 and $2.51 \mathrm{pm}$, respectively. On the whole, the absence of the $\mathrm{N}-\mathrm{H}$. $\cdot \mathrm{N}$ intramolecular hydrogen bond, the reduction of strength of the $\mathrm{C}=\mathrm{O} \cdots \mathrm{H}$ stabilizing interaction, and the presence of the $\mathrm{H}_{13} \cdots \mathrm{H}$ (ring) repulsive interaction in INA, as compared to the 
TABLE 2: Observed Frequencies for PA Monomer (Conformer I) in Argon and Xenon Matrix ${ }^{a}$

\begin{tabular}{|c|c|c|c|c|}
\hline approximate description & calculated frequency & intensity & observed $\operatorname{Ar}(10 \mathrm{~K})$ & observed Xe (20 K) \\
\hline$v\left(\mathrm{NH}_{2}\right)$ as & 3638.5 & 90.9 & $3545.9(\mathrm{M}) / 3542.5(\mathrm{~L})$ & $3533.6 / 3529.6$ \\
\hline$v\left(\mathrm{NH}_{2}\right) \mathrm{s}$ & 3500.0 & 45.9 & $3415.2(\mathrm{M}) / 3414.0(\mathrm{~L})$ & $3403.2 / 3399.0$ \\
\hline$v(\mathrm{C}-\mathrm{H})^{\prime} 1$ & 3142.6 & 2.1 & 3082.4 & 3068.2 \\
\hline$v(\mathrm{C}-\mathrm{H})^{\prime \prime} 1$ & 3124.3 & 11.7 & 3073.9 & 3062.3 \\
\hline$v(\mathrm{C}-\mathrm{H})^{\prime \prime 2}$ & 3106.0 & 8.3 & 3064.9 & 3054.6 \\
\hline$v(\mathrm{C}-\mathrm{H})^{\prime} 2$ & 3086.5 & 14.0 & 3018.6 & 3010.5 \\
\hline$v(\mathrm{C}=\mathrm{O})$ & 1714.8 & 354.9 & $\begin{array}{l}1723.7(\mathrm{~L}) / 1722.2(\mathrm{M}) / 1720.1(\mathrm{M}) / \\
1718.8(\mathrm{~L})\end{array}$ & 1714.9/1713.5/1711.2 \\
\hline$v$ ring 3 & 1593.1 & 13.1 & $1594.9(\mathrm{M}) / 1589.5(\mathrm{~L})$ & 1593.9/1586.2 \\
\hline$v$ ring 1 & 1575.6 & 24.2 & $1574.0(\mathrm{~L}) / 1572.5(\mathrm{M})$ & $1574.6 / 1571.6$ \\
\hline$\delta\left(\mathrm{NH}_{2}\right)$ & 1553.4 & 220.2 & $1552.8(\mathrm{~L}) / 1550.9(\mathrm{M})$ & 1547.5 \\
\hline$\delta(\mathrm{C}-\mathrm{H})^{\prime} 2$ & 1465.2 & 8.1 & $1472.9 / 1469.3 / 1462.4$ & $1472.8 / 1469.3 / 1463.6$ \\
\hline$\delta(\mathrm{C}-\mathrm{H})^{\prime \prime} 1$ & 1434.1 & 6.0 & $1443.6(\mathrm{M}) / 1442.4(\mathrm{~L})$ & 1441.4 \\
\hline$v(\mathrm{C}-\mathrm{N})$ & 1345.4 & 145.6 & $1366.0 / 1365.1$ & $1369.6 / 1365.2$ \\
\hline$\delta(\mathrm{C}-\mathrm{H})^{\prime} 1$ & 1288.9 & 7.7 & $1292.0(\mathrm{~L}) / 1291.0(\mathrm{M})$ & 1293.6/1289.6 \\
\hline$v$ ring 2 & 1266.1 & 18.0 & $1249.9(\mathrm{M}) / 1248.4(\mathrm{~L})$ & $1256.3 / 1251.4$ \\
\hline$v$ ring 5 & 1149.3 & 8.7 & 1157.9 & 1160.4 \\
\hline$\delta(\mathrm{C}-\mathrm{H})^{\prime \prime 2}$ & 1143.8 & 4.7 & 1143.9 & $1149.7 / 1142.6$ \\
\hline$v$ ring 6 & 1089.2 & 5.3 & 1084.0 & 1084.2 \\
\hline $\mathrm{w}\left(\mathrm{NH}_{2}\right)$ & 1067.1 & 0.7 & 1054.3 & 1045.2 \\
\hline$v$ ring 4 & 1038.3 & 9.5 & 1042.5 & 1039.6 \\
\hline$\gamma(\mathrm{C}-\mathrm{H})^{\prime} 2$ & 1000.7 & 0.3 & not observed & 1001.7 \\
\hline$\delta$ ring 1 & 994.5 & 7.2 & 999.1 & 998.9 \\
\hline$\gamma(\mathrm{C}-\mathrm{H})^{\prime \prime} 1$ & 966.0 & 0.8 & 965.7 & 964.9 \\
\hline$\gamma(\mathrm{C}-\mathrm{H})^{\prime \prime 2} 2$ & 907.7 & 1.0 & $930.6(\mathrm{M}) / 924.1(\mathrm{~L}) / 907.1(\mathrm{~L})$ & 933.6/903.6 \\
\hline$\gamma(\mathrm{C}=\mathrm{O})$ & 820.0 & 10.5 & $820.4 / 814.7 / 810.6$ & $819.0 / 817.1$ \\
\hline $\mathrm{v}(\mathrm{C}-\mathrm{C})$ & 762.3 & 0.8 & 768.4 & 770.1 \\
\hline$\gamma(\mathrm{C}-\mathrm{H})^{\prime} 1$ & 747.6 & 32.3 & $749.5(\mathrm{~L}) / 747.4(\mathrm{M})$ & $753.2 / 746.2$ \\
\hline$\tau$ ring 1 & 703.9 & 24.6 & $703.1(\mathrm{~L}) / 702.1(\mathrm{M})$ & 700.9 \\
\hline$\delta$ ring 2 & 628.5 & 1.0 & 624.4 & 622.2 \\
\hline$\tau(\mathrm{C}-\mathrm{N})$ & 616.3 & 8.7 & 615.5 & $616.5 / 614.7 / 612.2$ \\
\hline$\delta(\mathrm{C}=\mathrm{O})$ & 601.7 & 24.4 & $606.1(\mathrm{~L}) / 604.7(\mathrm{M}) / 602.8(\mathrm{M}) / 600.8(\mathrm{~L})$ & $607.2 / 603.9$ \\
\hline$\delta(\mathrm{C}-\mathrm{C}-\mathrm{N})$ & 483.8 & 2.3 & 481.2 & 489.7 \\
\hline$\tau$ ring 2 & 440.6 & 16.2 & $443.0 / 439.8$ & $439.5 / 436.3$ \\
\hline$\tau$ ring 3 & 405.0 & 4.6 & 403.5 & $\sim 400$ \\
\hline$\delta$ ring 3 & 370.7 & 0.5 & & \\
\hline$\gamma\left(\mathrm{NH}_{2}\right)$ & 316.4 & 194.6 & & \\
\hline $\mathrm{w}(\mathrm{C}-\mathrm{C})$ & 215.4 & 17.7 & & \\
\hline$\gamma(\mathrm{C}-\mathrm{C})$ & 152.3 & 2.1 & & \\
\hline$\tau(\mathrm{C}-\mathrm{C})$ & 72.7 & 3.2 & & \\
\hline
\end{tabular}

${ }^{a}$ B3LYP/6-311++G(d,p) calculated frequencies (scaled by 0.978$)$ and intensities are given for comparison. Frequencies in $\mathrm{cm}^{-1}$; calculated intensities in $\mathrm{km} \mathrm{mol}^{-1} . \nu$, bond stretching; $\delta$, bending; $\gamma$, rocking; $\tau$, torsion; w, wagging; s, symmetric; as, asymmetric; M, most stable site; $\mathrm{L}$, less stable site. In the $\mathrm{C}-\mathrm{H}$ stretching region, the observed spectra show bands of very low intensity, so that the proposed assignments must be considered tentative.

most stable conformer of PA, make the first molecule to be higher in energy than the latter by $26.2 \mathrm{~kJ} \mathrm{~mol}^{-1}$. It is worth mentioning that, as expected on the basis of the above considerations, DFT calculations undertaken at the same level of theory predicted the lowest energy conformer of NA as having an energy similar to that of INA and considerably higher than that of the most stable form of PA $\left(\Delta E_{(\mathrm{NA}-\mathrm{PA})}=22.9 \mathrm{~kJ}\right.$ $\left.\mathrm{mol}^{-1}\right)$.

The DFT potential energy profile for internal rotation about the $\mathrm{C}_{11}-\mathrm{C}_{4}$ bond of INA is depicted in Figure 2B. Four equivalent-by-symmetry minima are observed, being separated from each other by barriers of 11.3 and $1.3 \mathrm{~kJ} \mathrm{~mol}^{-1}$. In the minimum energy configurations, the planes of the carboxamide group and pyridine ring make an angle of $23.7^{\circ}$ (DFT value; $25.1^{\circ}$ at the MP2 level), and the aromatic ring is nearly planar (deviations from planarity of the dihedral angles associated with the ring are less than $3^{\circ}$; Table S2), while the amide nitrogen atom is predicted to be somewhat pyramidalized (the $\mathrm{H}-\mathrm{N}(-$ C) $-\mathrm{H}$ dihedral angle is predicted by the DFT and MP2 calculations to be 157.2 and $146.1^{\circ}$, respectively). It is interesting that the calculated angle between the carboxamide and the pyridine ring in the isolated molecule of INA is similar to those found in the known crystalline modifications of the compound $\left(30.5^{\circ}\right.$ in crystal $\mathrm{I}$ and 25.4 and $24.0^{\circ}$ in crystal $\mathrm{II}^{17}$ ).
Vibrational Spectra. IR Spectra of the As-Deposited Matrixes. Both PA and INA have 39 fundamental vibrations, all being active in the infrared. Table S3 displays the definition of symmetry coordinates of PA used in the normal coordinates analysis undertaken in this study. The DFT calculated spectra for the two conformers of PA and potential energy distributions (PED) are given in Tables S4 and S5. Table S6 shows the chosen symmetry coordinates for INA, and Table S7 presents the calculated spectra and PEDs for this molecule. The proposed band assignments for the IR spectra of the two studied compounds isolated in argon and xenon matrixes are given in Tables 2 and 3 .

Figures 3 and 4 depict the as-deposited spectra of PA and INA, respectively, trapped in argon and xenon matrixes obtained immediately after deposition at 10 and $20 \mathrm{~K}$ and the relevant calculated spectra. In the case of PA, only the most stable conformer (I) was taken into consideration because the population of the higher energy conformer was predicted by the calculations to be negligible $(<0.0001 \%$ at $323 \mathrm{~K}$, the temperature of the valve nozzle during deposition). As seen in Figure 3 , the calculated spectrum for conformer I fits nicely with the experimental one, making the assignment of the bands straightforward. The calculated spectrum for the stable structure of INA 
TABLE 3: Observed Frequencies for the INA Monomer in Argon and Xenon Matrix ${ }^{a}$

\begin{tabular}{|c|c|c|c|c|}
\hline approximate description & calculated frequency & intensity & observed $\operatorname{Ar}(10 \mathrm{~K})$ & observed Xe (20 K) \\
\hline$v\left(\mathrm{NH}_{2}\right)$ as & 3632.1 & 43.5 & $3558.2 / 3556.4 / 3552.2 / 3551.2$ & $3540.2 / 3534.0$ \\
\hline$v\left(\mathrm{NH}_{2}\right) \mathrm{s}$ & 3508.7 & 46.6 & $3443.3 / 3438.4 / 3436.9 / 3435.2$ & $3427.3 / 3422.6 / 3419.0$ \\
\hline$v(\mathrm{C}-\mathrm{H})^{\prime \prime} 1$ & 3135.2 & 2.3 & not observed & not observed \\
\hline$v(\mathrm{C}-\mathrm{H})^{\prime \prime 2} 2$ & 3112.3 & 9.4 & 3084.5 & 3073.1 \\
\hline$v(\mathrm{C}-\mathrm{H})^{\prime} 1$ & 3088.6 & 13.5 & 3056.8 & 3069.2 \\
\hline$v(\mathrm{C}-\mathrm{H})^{\prime} 2$ & 3082.7 & 18.9 & 3040.8 & 3055.8 \\
\hline$v(\mathrm{C}=\mathrm{O})$ & 1714.1 & 331.6 & $1719.8 / 1718.0 / 1717.0 / 1716.2 / 1715.4$ & 1711.0/1709.3/1707.9 \\
\hline$v \operatorname{ring} 3$ & 1597.1 & 2.0 & 1588.6 & 1585.6 \\
\hline$\delta\left(\mathrm{NH}_{2}\right)$ & 1583.6 & 141.4 & 1580.6 & $1577.8 / 1570.8$ \\
\hline$v$ ring 5 & 1562.0 & 38.2 & 1565.3 & 1558.6 \\
\hline$v$ ring 6 & 1487.3 & 1.2 & 1507.0 & not observed \\
\hline$\delta(\mathrm{C}-\mathrm{H})^{\prime} 1$ & 1406.5 & 22.6 & $1410.1 / 1406.9$ & 1407.3 \\
\hline$v(\mathrm{C}-\mathrm{N})$ & 1331.7 & 195.5 & 1355.2 & 1359.7 \\
\hline$\delta(\mathrm{C}-\mathrm{H})^{\prime \prime 2} 2$ & 1317.7 & 38.3 & 1323.3 & 1320.4 \\
\hline$v$ ring 2 & 1248.8 & 5.8 & 1239.4 & 1227.1 \\
\hline$\delta(\mathrm{C}-\mathrm{H})^{\prime} 2$ & 1215.5 & 1.4 & 1207.8 & 1203.4 \\
\hline$\delta$ ring 1 & 1123.9 & 4.4 & 1133.9 & 1141.6 \\
\hline$v$ ring 4 & 1088.7 & 0.8 & 1097.0 & 1096.5 \\
\hline$\delta(\mathrm{C}-\mathrm{H})^{\prime \prime} 1$ & 1065.8 & 5.4 & 1065.8 & 1068.5 \\
\hline $\mathrm{w}\left(\mathrm{NH}_{2}\right)$ & 1058.2 & 5.3 & 1063.2 & 1064.6 \\
\hline$v$ ring 1 & 989.1 & 3.2 & 993.7 & 992.7 \\
\hline$\gamma(\mathrm{C}-\mathrm{H})^{\prime \prime} 2$ & 984.7 & 0.9 & 990.2 & not observed \\
\hline$\gamma(\mathrm{C}-\mathrm{H})^{\prime \prime} 1$ & 960.6 & 0.4 & not observed & not observed \\
\hline$\gamma(\mathrm{C}-\mathrm{H})^{\prime} 1$ & 874.9 & 2.6 & 873.6 & 872.1 \\
\hline$\gamma(\mathrm{C}-\mathrm{H})^{\prime} 2$ & 838.5 & 14.8 & 838.5 & $843.4 / 839.8$ \\
\hline$\tau$ ring 1 & 753.9 & 17.9 & 750.4 & $754.0 / 751.4$ \\
\hline$v(\mathrm{C}-\mathrm{C})$ & 749.9 & 3.2 & 747.9 & 748.1 \\
\hline$\gamma(\mathrm{C}=\mathrm{O})$ & 707.9 & 30.1 & 703.4 & $710.7 / 706.6 / 702.3$ \\
\hline$\delta$ ring 3 & 666.5 & 0.9 & 680.1 & 651.7 \\
\hline$\delta(\mathrm{C}=\mathrm{O})$ & 604.0 & 34.0 & $605.4 / 603.4$ & 606.8 \\
\hline$\tau(\mathrm{C}-\mathrm{N})$ & 550.2 & 7.8 & $544.8 / 541.4$ & 532.4 \\
\hline$\delta(\mathrm{C}-\mathrm{C}-\mathrm{N})$ & 500.6 & 5.9 & $502.6 / 497.6$ & 497.9 \\
\hline$\tau$ ring 3 & 404.8 & 21.9 & 418.0 & 416.8 \\
\hline$\tau$ ring 2 & 377.1 & 0.1 & & \\
\hline$\delta$ ring 2 & 359.6 & 6.0 & & \\
\hline$\gamma\left(\mathrm{NH}_{2}\right)$ & 333.5 & 170.7 & & \\
\hline $\mathrm{w}(\mathrm{C}-\mathrm{C})$ & 206.9 & 10.6 & & \\
\hline$\gamma(\mathrm{C}-\mathrm{C})$ & 146.3 & 4.8 & & \\
\hline$\tau(\mathrm{C}-\mathrm{C})$ & 55.2 & 7.3 & & \\
\hline
\end{tabular}

${ }^{a}$ B3LYP/6-311++G(d,p) calculated frequencies (scaled by 0.978) and intensities are given for comparison. Frequencies in $\mathrm{cm}^{-1}$; calculated intensities in $\mathrm{km} \mathrm{mol}^{-1} . \nu$, bond stretching; $\delta$, bending; $\gamma$, rocking; $\tau$, torsion; w, wagging; s, symmetric; as, asymmetric; M, most stable site; L, less stable site. In the $\mathrm{C}-\mathrm{H}$ stretching region, the observed spectra show bands of very low intensity, so that the proposed assignments must be considered tentative.

shows also a very good agreement with the experimental spectrum (Figure 4).

The experimental data revealed that the PA molecule occupies two main distinct matrix sites in argon matrix, one of them being considerably more stable than the other. This could be clearly seen during the performed annealing experiments, in which aggregation was observed to proceed differently depending on the specific matrix site initially occupied by the PA monomers. Indeed, upon annealing of the argon matrix the IR bands associated with the most stable matrix site practically did not decrease in intensity until a temperature of ca. $40 \mathrm{~K}$ was reached, while those corresponding to the less stable site started to lose intensity at a temperature as low as $24 \mathrm{~K}$ (Figure 5). At $36 \mathrm{~K}$, the bands related to the less stable site have almost disappeared, whereas those related to the most stable site have kept their intensity practically unchanged.

In the xenon matrix, PA also occupies two main sites (Table 2 ), but these seem to have very similar energies, since upon annealing of this matrix the observed aggregation was found to be independent of the site initially occupied by the PA monomers.

Some of the bands observed in the spectra of INA also exhibit splitting that, with all probability, is also due to the existence of different occupancy sites. However, for this molecule the stability of the different sites seems to be similar in both argon and xenon matrixes, at least taking into consideration the results of the annealing experiments, which did not reveal any dependence of aggregation with the initially occupied site.

It is interesting that the observed vibrational spectra for PA and INA provide clear information on the main structural difference between these two compounds, as mentioned before, the $\mathrm{NH}_{2} \cdots \mathrm{N}$ (ring) interaction, which is only present in PA. In fact, as expected, the $v \mathrm{NH}_{2}$ vibrations (both symmetric and antisymmetric modes) were observed at lower frequencies in $\mathrm{PA}$, while the $\nu \mathrm{C}-\mathrm{N}, \mathrm{wNH}_{2}$, and $\tau \mathrm{C}-\mathrm{N}$ modes absorb at higher frequencies in this molecule, comparatively to INA. All these trends are in agreement with the electronic charge migration from the $\mathrm{N}_{(12)}-\mathrm{H}_{(13)}$ bond to the intramolecular $\mathrm{H}$-bond in PA (thus the frequencies of the $v \mathrm{NH}_{2}$ vibrations decrease), which is partially compensated by the increase in the electronic density of the $\mathrm{C}_{(11)}-\mathrm{N}_{(12)}$ bond ( $v \mathrm{C}-\mathrm{N}$ frequency increases), and with the increase in the rigidity of the molecule toward deformation of the $\mathrm{H}_{(13)}-\mathrm{N}_{(12)}-\mathrm{C}_{(11)}-\mathrm{C}_{(2)}-\mathrm{N}_{(1)}$ intramolecularly H-bonded five-membered ring (then, $\mathrm{wNH}_{2}$ and $\tau \mathrm{C}-\mathrm{N}$ modes increase in frequency). The calculated relative frequencies for the $\tau(\mathrm{C}-\mathrm{C})$ vibration (not accessible experimentally under the present experimental conditions) in the two molecules are also in agreement with an increased rigidity of the $\mathrm{H}_{(13)}-\mathrm{N}_{(12)}-\mathrm{C}_{(11)}-$ 


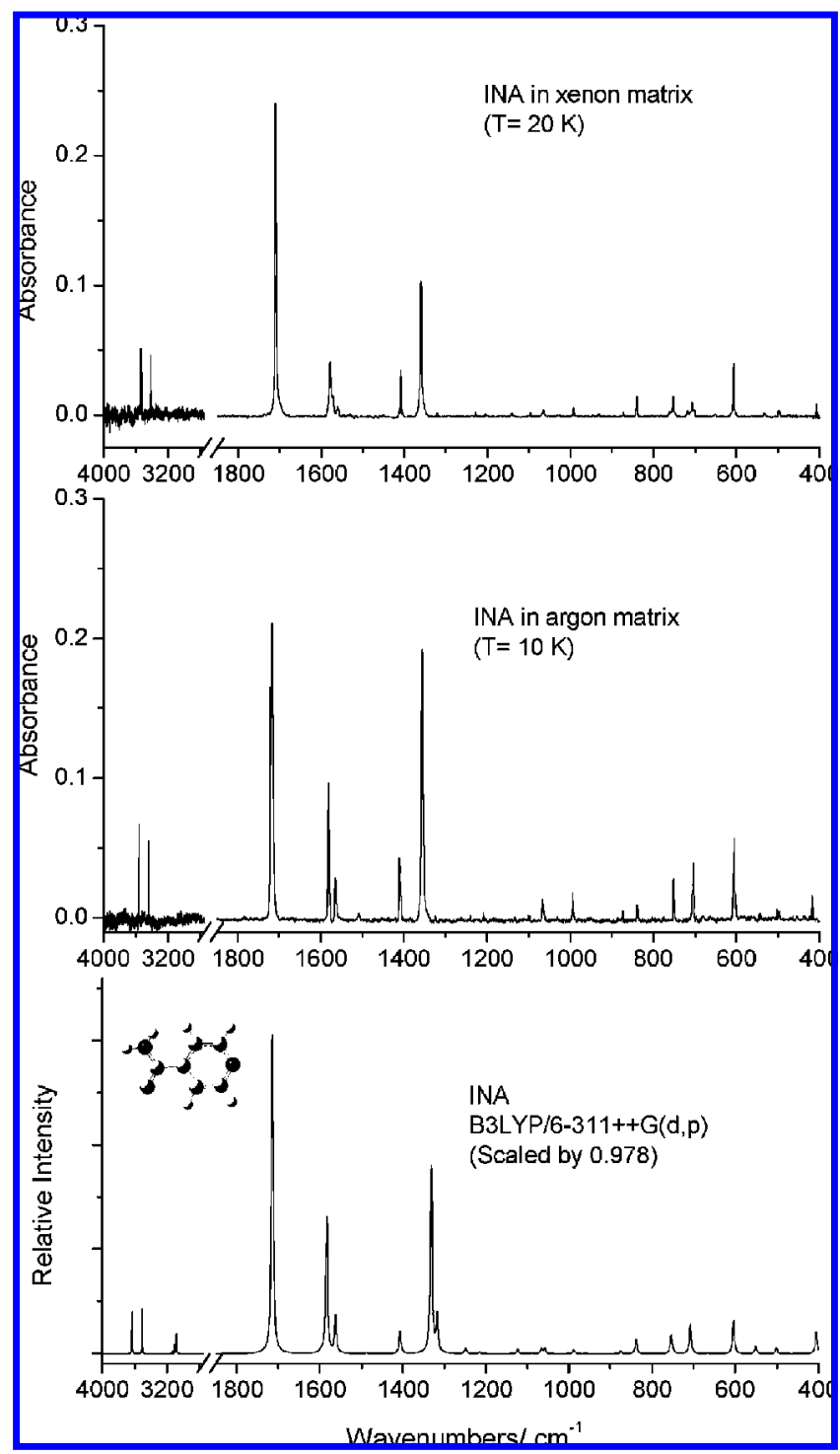

Figure 4. Infrared spectra of INA trapped in argon and xenon matrixes obtained immediately after deposition at 10 and $20 \mathrm{~K}$, respectively, and DFT(B3LYP)/6-311++G(d,p) calculated spectrum (scaled by 0.978 ) for the minimum energy conformation of the INA molecule.

$\mathrm{C}_{(2)}-\mathrm{N}_{(1)}$ fragment in PA [ $\left.\tau(\mathrm{C}-\mathrm{C}): 72.7 \mathrm{~cm}^{-1}\right]$ compared to INA $\left[\tau(\mathrm{C}-\mathrm{C}): 55.2 \mathrm{~cm}^{-1}\right]$, as are the barriers to amide rotational barriers obtained previously for the two compounds by NMR $\left(\Delta H=76.6\right.$ and $59.0 \mathrm{~kJ} \mathrm{~mol}^{-1}$, for Pa and INA, respectively ${ }^{11,12}$ ). Regarding these trends, only the relative frequencies of the $\delta \mathrm{NH}_{2}$ mode in PA and INA appear to be opposite of the expectations, with that of PA appearing at a lower value than that of INA (Tables 2 and 3). This apparent discrepancy, however, shall result from the fact that in $\mathrm{PA}$ the $\mathrm{NH}_{2}$ group is planar, while in INA it is, as mentioned before, somewhat pyramidalized [it is well known, for instance, that $\delta \mathrm{NH}_{2}$ occurs at higher frequencies in primary amines (ca. $1600-1650 \mathrm{~cm}^{-1}$ ) than in amides (ca. 1540-1600)].

Neat Solid-State Vibrational Spectra of PA and INA. As mentioned in the Introduction, the IR spectra of PA and INA have been studied previously in the neat solid state (noncharacterized crystal modifications in $\mathrm{KBr}$ pellets at room temperature, in some cases supported by theoretical calculations of the spectra of the single molecule ${ }^{13-15,18}$ ). In the present study, in addition to the IR spectra of the phase $\alpha$ of each compound, ${ }^{16,17}$ low-temperature neat solid-state IR spectra of PA and INA were investigated. For the two compounds, both the

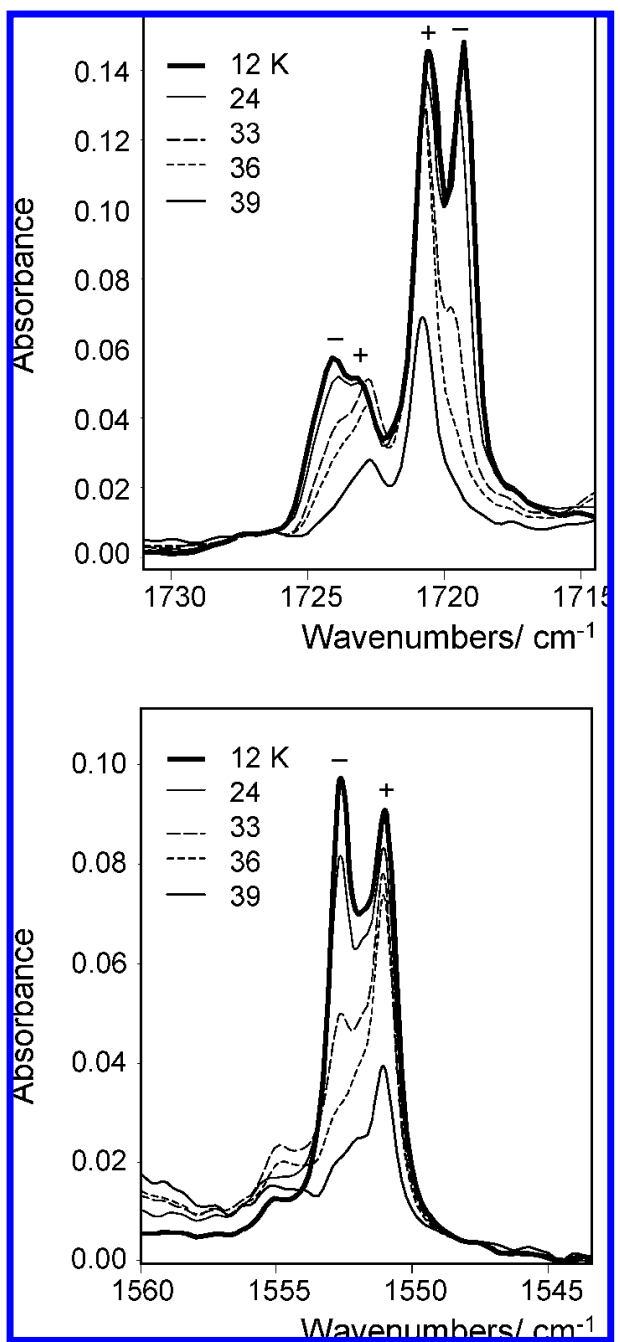

Figure 5. Selected spectral regions of the infrared spectra of PA in an argon matrix obtained during the annealing experiments. This picture clearly shows the presence of two main matrix sites with different stability. Bands originated in PA in the most stable matrix site are indicated by the "+" sign, whereas bands due to PA molecule in the less stable matrix site are labeled with a "-" sign.

glassy state resulting from fast deposition of the vapor of the substance onto the cold substrate of the cryostat kept at $10 \mathrm{~K}$ during deposition and the crystal obtained upon annealing of the glass were characterized spectroscopically. The obtained spectra are shown in Figures 6 and 7, and the assignments are given in Tables 4 and 5. The interpretation of the IR spectra of the solid-state phases took advantage of the spectroscopic data now obtained for the matrix-isolated compounds and from our accumulated experience regarding the main changes in the spectra associated with the change from the matrix environment to the neat solid phases, in particular those determined by $\mathrm{H}$-bond interactions in the latter. ${ }^{38-48}$

In Tables 4 and 5, the frequency shifts in going from the spectra of matrix-isolated PA and INA to the spectra of the compounds in the crystalline phase at low temperature are presented. It is clear from these results that the frequencies of the modes localized in the aromatic ring practically do not change (absolute shifts less than $20 \mathrm{~cm}^{-1}$; \% shifts less than $2 \%)$. On the other hand, those associated with the amide group change considerably, reflecting the involvement of this group in H-bond interactions in the crystal. Accordingly, the bands due to the $\mathrm{NH}_{2}$ and $\mathrm{C}=\mathrm{O}$ stretching modes show the usual shift to lower frequencies (accompanied by extensive broadening and 


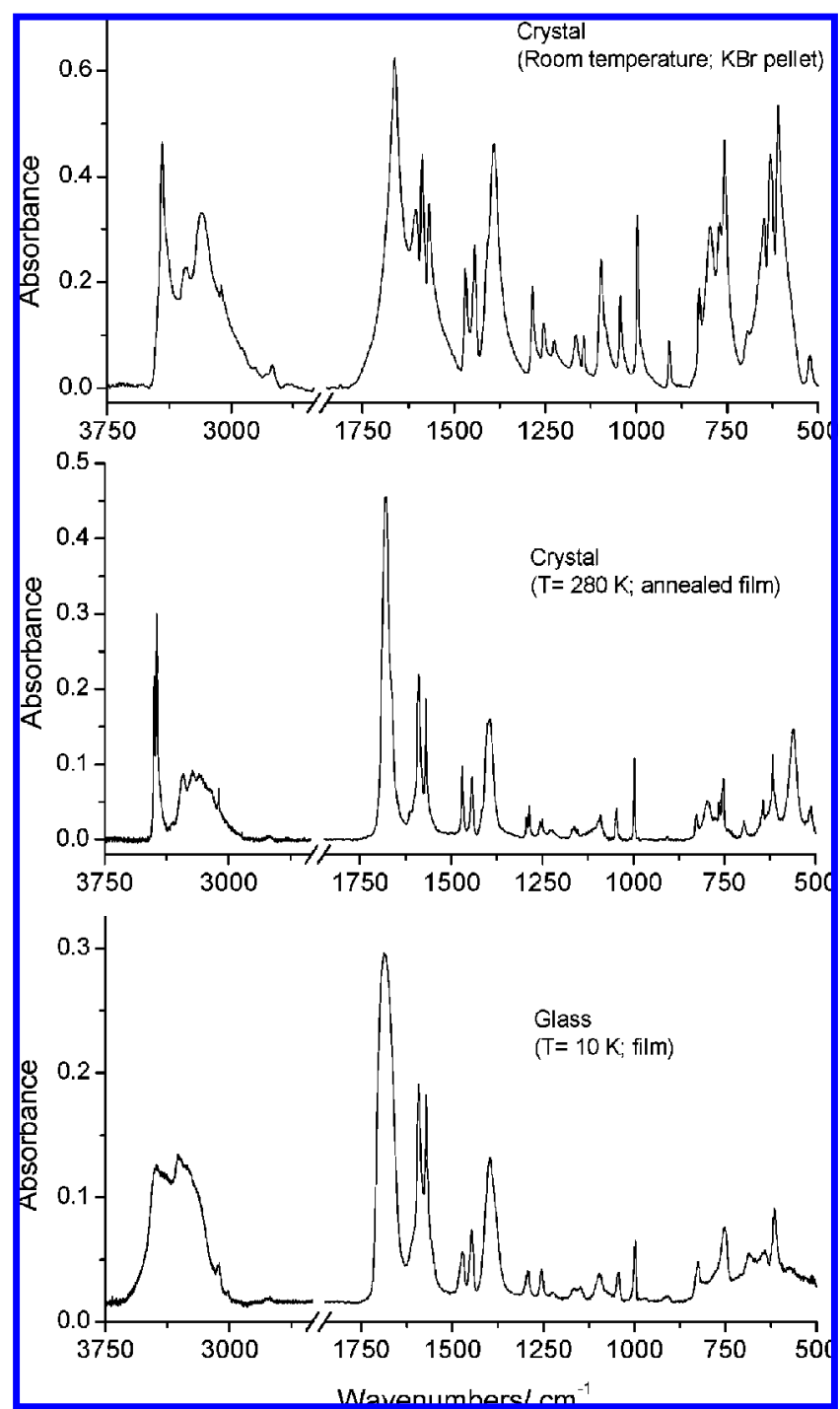

Figure 6. Infrared spectra of PA in the glassy state resulting from fast deposition of the vapor of the compound onto the cryostat's cold substrate at $10 \mathrm{~K}$ (bottom), in the crystalline state resulting from annealing of the glassy film up to $T=280 \mathrm{~K}$ (mid), and in the roomtemperature crystalline phase in $\mathrm{KBr}$ pellet (top).

intensification), while the $\delta \mathrm{NH}_{2}$, $\mathrm{wNH}_{2}, \gamma \mathrm{NH}_{2}, \gamma \mathrm{C}=\mathrm{O}, \delta \mathrm{C}=$ $\mathrm{O}$, and $\tau \mathrm{C}-\mathrm{N}$ deformational modes shift to higher frequencies, as expected taking into consideration the increase in the rigidity of the molecule toward deformation due to the H-bonding. The observed increase in the $\mathrm{C}-\mathrm{N}$ stretching frequency (Tables 4 and 5) could also be anticipated since the involvement of the amide group in intermolecular $\mathrm{H}$-bonding in the neat solid state, and the associated decrease in the electronic density in the $\mathrm{N}-\mathrm{H}$ bonds it implies, induces a compensatory increase in the electronic density of the amide $\mathrm{C}-\mathrm{N}$ bond, thus leading to the observed shift to a higher frequency of the $\nu \mathrm{C}-\mathrm{N}$ vibration.

Among the observed frequency shifts and band profile changes, the most pronounced occur for the two $\mathrm{NH}_{2}$ stretching modes and for the $\tau \mathrm{C}-\mathrm{N}$ and $\gamma \mathrm{NH}_{2}$ vibrations (Figures 6 and 7 and Tables 4 and 5). The influence of the H-bonding interactions in these two types of vibrations has in fact been extensively studied in the past and is well known to be extremely important, the observed magnitude of the frequency shifts reflecting the strength of the H-bonds. ${ }^{38-40,42,44,46-48}$ By comparing the results obtained for the two compounds and for each

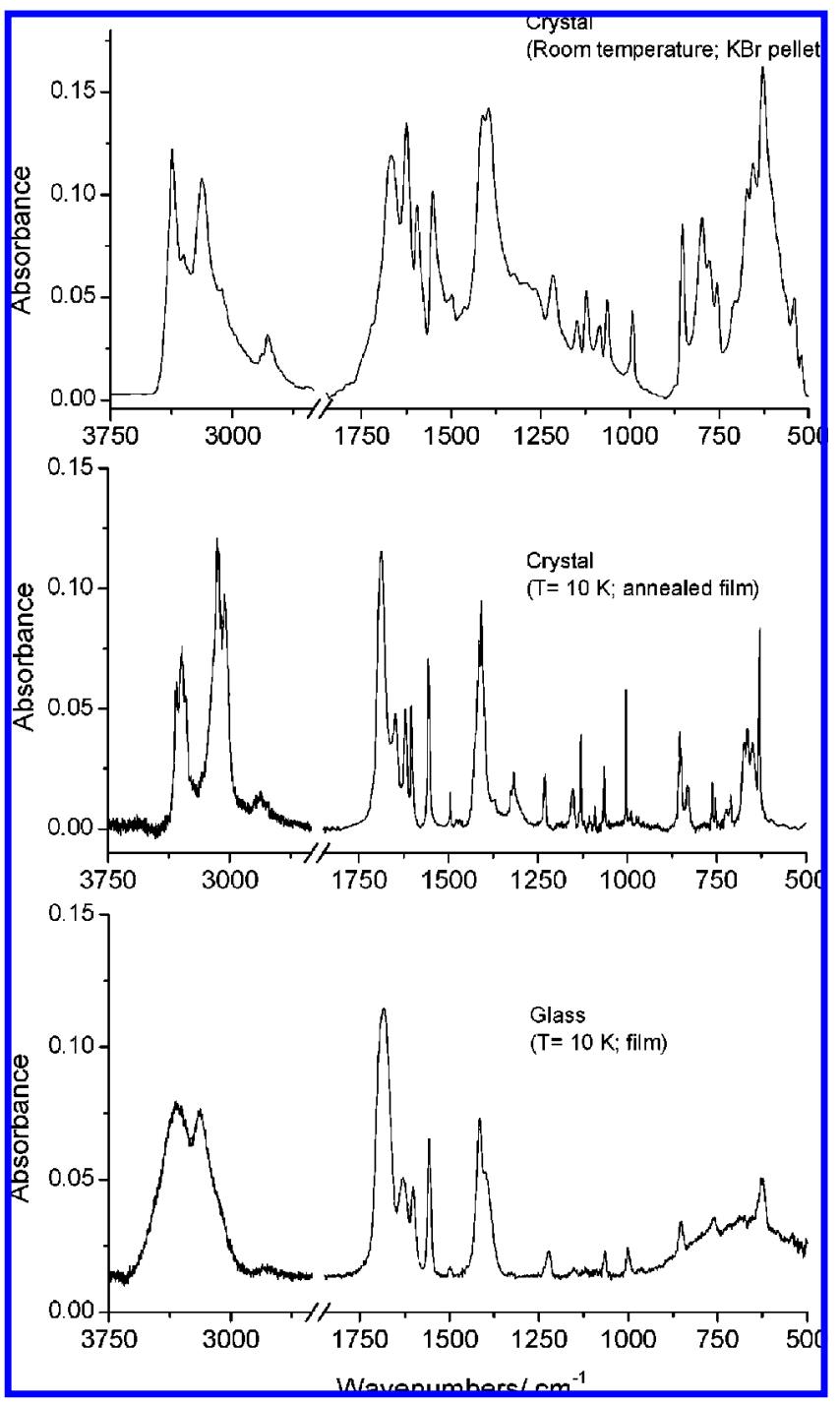

Figure 7. Infrared spectra of INA in the glassy state resulting from fast deposition of the vapor of the compound onto the cryostat's cold substrate at $10 \mathrm{~K}$ (bottom), in the crystalline state resulting from annealing of the glassy film to $280 \mathrm{~K}$ and recooling it to $10 \mathrm{~K}$ (mid), and in the room-temperature crystalline phase in $\mathrm{KBr}$ pellet (top).

compound relative to the different phases (glass, low-temperature crystal, and room-temperature crystal), the following conclusions can be drawn:

(a) The intermolecular H-bonds in INA are stronger than those in PA (frequency shifts in the $v \mathrm{NH}_{2}$ region are -110 and -190 $\mathrm{cm}^{-1}$ for PA and -254 and $-388 \mathrm{~cm}^{-1}$ for INA; in the $\tau \mathrm{C}-\mathrm{N}$ and $\gamma \mathrm{NH}_{2}$ region, 171 and $271 \mathrm{~cm}^{-1}$ for PA and 286 and 316 $\mathrm{cm}^{-1}$ for INA; Tables 4 and 5). This result agrees well with the relative melting point of the two compounds ( $\alpha$ phases: $107-110^{\circ} \mathrm{C}$ for PA and $156^{\circ} \mathrm{C}$ for INA ${ }^{17}$ ).

(b) For both PA and INA, the most sensitive bands to $\mathrm{H}$-bonding are considerably broader in the glassy than those in the crystalline states (this is particularly noticeable for $\tau \mathrm{C}-\mathrm{N}$ and $\gamma \mathrm{NH}_{2}$, but it is also clearly evident in the $v \mathrm{NH}_{2}$ region; Figures 6 and 7). This result agrees with the greater short-range heterogeneity of the glassy phase compared with the ordering of the crystalline phases. It is noteworthy that the bands due to the $\tau \mathrm{C}-\mathrm{N}$ and $\gamma \mathrm{NH}_{2}$ modes are well visible in the spectra of the crystalline phases, whereas in the glassy state they give rise to the broad unstructured band observed in the spectra of both compounds that extend from ca. 900 to below $500 \mathrm{~cm}^{-1}$ (Figures 6 and 7). 
TABLE 4: Observed Frequencies for the Neat PA Solid in the Glassy State Resulting from Fast Deposition of the Vapor of the Compound onto the Cryostat's Cold Substrate at $10 \mathrm{~K}$, in the Crystalline State Resulting from Annealing of the Glassy Film (T $=280 \mathrm{~K}$ ), and in the Room-Temperature Crystalline Phase (in KBr Pellet) ${ }^{a}$

\begin{tabular}{|c|c|c|c|c|}
\hline $\begin{array}{l}\text { approximate } \\
\text { description }^{b}\end{array}$ & $\begin{array}{c}\text { crystal } \\
\text { (KBr pellet, room temp) }\end{array}$ & $\begin{array}{c}\text { glass } \\
\text { (film, } 10 \mathrm{~K})\end{array}$ & $\begin{array}{c}\text { crystal } \\
\text { (film, } 280 \mathrm{~K} \text { ) }\end{array}$ & $\begin{array}{c}\text { frequency shift } \\
\text { (crystalline film at } 280 \mathrm{~K}, \mathrm{Ar} \text { matrix })^{c}\end{array}$ \\
\hline$v\left(\mathrm{NH}_{2}\right)$ as & $3417 / 3385$ & $3448 / 3392$ & $3450 / 3435 / 3430 / 3420$ & -110 \\
\hline$v\left(\mathrm{NH}_{2}\right) \mathrm{s}$ & $3271 / 3185$ & $3304 / 3256 / 3188$ & $3343 / 3276 / 3218 / 3171 / 3114$ & -190 \\
\hline$v(\mathrm{C}-\mathrm{H})^{\prime} 1$ & 3079 & not observed & not observed & $-3^{d}$ \\
\hline$v(\mathrm{C}-\mathrm{H})^{\prime \prime} 1$ & 3061 & 3068 & 3060 & -14 \\
\hline$v(\mathrm{C}-\mathrm{H})^{\prime \prime 2} 2$ & 3042 & & & -5 \\
\hline$v(\mathrm{C}-\mathrm{H})^{\prime} 2$ & 3016 & 3013 & not observed & $-3^{d}$ \\
\hline$v(\mathrm{C}=\mathrm{O})$ & 1662 & 1686 & $1679 / 1666$ & -49 \\
\hline$v$ ring 3 & 1587 & 1591 & $1591 / 1589$ & -2 \\
\hline$v$ ring 1 & 1568 & 1571 & 1570 & -3 \\
\hline$\delta\left(\mathrm{NH}_{2}\right)$ & $1603 / \sim 1583$ & $\sim 1583$ & $1612 / \sim 1582$ & 45 \\
\hline$\delta(\mathrm{C}-\mathrm{H})^{\prime} 2$ & 1468 & 1471 & 1469 & 1 \\
\hline$\delta(\mathrm{C}-\mathrm{H})^{\prime \prime} 1$ & 1443 & 1446 & $1447 / 1442$ & 2 \\
\hline$v(\mathrm{C}-\mathrm{N})$ & $1406 / 1390$ & $1397 / 1386$ & $1415 / 1401 / 1395$ & 38 \\
\hline$\delta(\mathrm{C}-\mathrm{H})^{\prime} 1$ & 1284 & 1293 & $1293 / 1286$ & -2 \\
\hline$v$ ring 2 & 1253 & 1254 & $1257 / 1250$ & 4 \\
\hline$v$ ring 5 & 1165 & 1165 & $1168 / 1163$ & 8 \\
\hline$\delta(\mathrm{C}-\mathrm{H})^{\prime \prime 2}$ & 1143 & 1147 & 1153 & 9 \\
\hline$v$ ring 6 & $1096 / 1084$ & 1097 & $1098 / 1091$ & 11 \\
\hline $\mathrm{w}\left(\mathrm{NH}_{2}\right)$ & 1225 & 1224 & $1228 / 1222$ & 171 \\
\hline$v$ ring 4 & 1043 & 1043 & $1049 / 1046$ & 5 \\
\hline$\gamma(\mathrm{C}-\mathrm{H})^{\prime} 2$ & not observed & not observed & not observed & \\
\hline$\delta$ ring 1 & 996 & 998 & 997 & -2 \\
\hline$\gamma(\mathrm{C}-\mathrm{H})^{\prime \prime} 1$ & 986 & 974 & 985 & 19 \\
\hline$\gamma(\mathrm{C}-\mathrm{H})^{\prime \prime 2} 2$ & 909 & 911 & 907 & -14 \\
\hline$\gamma(\mathrm{C}=\mathrm{O})$ & 826 & 824 & 827 & 12 \\
\hline$v(\mathrm{C}-\mathrm{C})$ & 770 & not observed & 764 & -4 \\
\hline$\gamma(\mathrm{C}-\mathrm{H})^{\prime} 1$ & 756 & 752 & $756 / 753$ & 6 \\
\hline$\tau$ ring 1 & 694 & 685 & 696 & -7 \\
\hline$\delta$ ring 2 & 649 & 644 & 644 & 20 \\
\hline$\tau(\mathrm{C}-\mathrm{N})$ & 796 & $\sim 779$ & $796 / 777$ & 171 \\
\hline$\delta(\mathrm{C}=\mathrm{O})$ & 610 & 615 & 617 & 13 \\
\hline$\delta(\mathrm{C}-\mathrm{C}-\mathrm{N})$ & 522 & 512 & 513 & 32 \\
\hline $\begin{array}{l}\tau \text { ring } 2 \\
\tau \text { ring } 3\end{array}$ & \multirow{6}{*}{630} & \multirow{6}{*}{$\sim 570$} & \multirow{6}{*}{$614 / 561$} & \multirow{6}{*}{271} \\
\hline$\delta$ ring 3 & & & & \\
\hline$\gamma\left(\mathrm{NH}_{2}\right)$ & & & & \\
\hline $\mathrm{w}(\mathrm{C}-\mathrm{C})$ & & & & \\
\hline$\gamma(\mathrm{C}-\mathrm{C})$ & & & & \\
\hline$\tau(\mathrm{C}-\mathrm{C})$ & & & & \\
\hline
\end{tabular}

${ }^{a}$ Frequencies in $\mathrm{cm}^{-1}$; calculated intensities in $\mathrm{km} \mathrm{mol}^{-1} . \nu$, bond stretching; $\delta$, bending; $\gamma$, rocking; $\tau$, torsion; w, wagging; $\mathrm{s}$, symmetric; as, asymmetric. ${ }^{b}$ The order of the modes in this table was chosen to be the same as that in Table 2, for better comparison of the results obtained in the neat solid phases and for the matrix isolated molecule (and also with the calculated frequencies). ${ }^{c}$ The frequency shifts were calculated using the average values of all bands assigned to a given mode, for features observed in both the crystalline state and in the matrix isolated compound. ${ }^{d}$ Frequency for the crystalline state taken from the spectrum of the room-temperature crystal.

(c) Also for both compounds, the spectrum of the lowtemperature crystal clearly reveals the smaller mobility of the molecules when compared with that of the room-temperature crystal. This reflects in the considerably smaller width of the bands in the spectra obtained at low temperature. In turn, this leads to a higher intrinsic spectral resolution, allowing for observation of fine details of the spectra of the low-temperature crystal, such as extensive band splitting, which correlates with the complexity of the crystalline networks in the two molecules. ${ }^{16,17}$

UV-Induced Photochemistry for the Compounds in Matrixes. Upon broad-band UV irradiation $(\lambda>235 \mathrm{~nm})$ of matrixisolated monomeric PA, the spectrum of the compound rapidly lost intensity, while new bands due to photoproducts developed. The most prominent features of the photoproducts were observed in the $2300-2100 \mathrm{~cm}^{-1}$ spectral range, though other features could also been observed in both the low- and high-frequency spectral regions, as shown in Figure 8. The proposed set of photoinduced processes is depicted in Figure 9. The assignments of the new bands in the spectra of the irradiated matrixes are given in Table 6, where they are compared with the calculated
[B3LYP/6-311G++G(d,p)] frequencies for the photoproducts as well as with those previously reported for these compounds isolated in an argon matrix. ${ }^{49-52}$ Since the experiments carried out for PA in argon and xenon matrixes yielded essentially the same results, the following discussion will focus on the results obtained in argon.

Observation in the spectra of the irradiated PA matrixes of the intense, broad, and structured new band at $2300-2200 \mathrm{~cm}^{-1}$ is a clear indication of the photoproduction of isocyanic acid (HNCO), ${ }^{49,50}$ which also gives rise to the bands observed at 3530/3527/3525, 3514, 3496, 777, and $569 \mathrm{~cm}^{-1}$. Bands at similar frequencies have been observed previously for $\mathrm{HNCO}$ isolated in argon. ${ }^{49,50}$ According to Teles et al., ${ }^{49}$ the bands at 3514 and $3496 \mathrm{~cm}^{-1}$ correspond to a Fermi doublet involving coupling of the $v \mathrm{~N}-\mathrm{H}$ stretching mode and the combination $v \mathrm{NCO}$ as $+\delta \mathrm{HNC}+\delta \mathrm{NCO}$, while the triplet at slightly higher frequencies corresponds to $v \mathrm{~N}-\mathrm{H}$ of rotating $\mathrm{HNCO}$ molecules (fundamental vibrational transition coupled with the $1 \leftarrow 0$ rotational transition). On the other hand, the 777 and $568 \mathrm{~cm}^{-1}$ bands are due to the $\delta \mathrm{HNC}$ and $\delta \mathrm{NCO}$ modes, respectively. It is important to notice that the frequencies now observed for 
TABLE 5: Observed Frequencies for the Neat INA Solid in the Glassy State Resulting from Fast Deposition of the Vapor of the Compound onto the Cryostat's Cold Substrate at $10 \mathrm{~K}$, in the Crystalline State Resulting from Annealing of the Glassy Film to $280 \mathrm{~K}$ and Recooling It to $10 \mathrm{~K}$, and in the Room-Temperature Crystalline Phase (in KBr Pellet) ${ }^{a}$

\begin{tabular}{|c|c|c|c|c|}
\hline $\begin{array}{l}\text { approximate } \\
\text { description }^{b}\end{array}$ & $\begin{array}{c}\text { crystal } \\
\text { (KBr pellet, room temp) }\end{array}$ & $\begin{array}{c}\text { glass } \\
\text { (film, } 10 \mathrm{~K})\end{array}$ & $\begin{array}{c}\text { crystal } \\
(\text { film, } 10 \mathrm{~K})^{c}\end{array}$ & $\begin{array}{c}\text { frequency shift } \\
{(\text { crystalline film at } 10 \mathrm{~K}, \text { Ar matrix })^{d}}^{d}\end{array}$ \\
\hline$v\left(\mathrm{NH}_{2}\right)$ as & $3371 / 3300$ & 3333 & $3330 / 3295 / 3275$ & -254 \\
\hline$v\left(\mathrm{NH}_{2}\right) \mathrm{s}$ & 3189 & 3191 & $3070 / 3030$ & -388 \\
\hline$v(\mathrm{C}-\mathrm{H})^{\prime \prime} 1$ & not observed & not observed & not observed & \\
\hline$v(\mathrm{C}-\mathrm{H})^{\prime \prime 2}$ & not observed & not observed & not observed & \\
\hline$v(\mathrm{C}-\mathrm{H})^{\prime} 1$ & 3078 & 3074 & 3077 & 20 \\
\hline$v(\mathrm{C}-\mathrm{H})^{\prime} 2$ & 3065 & 3074 & 3065 & 24 \\
\hline$v(\mathrm{C}=\mathrm{O})$ & 1667 & 1682 & $1687 / 1648$ & -50 \\
\hline$v \operatorname{ring} 3$ & 1594 & 1602 & 1603 & 14 \\
\hline$\delta\left(\mathrm{NH}_{2}\right)$ & 1625 & 1630 & 1620 & 39 \\
\hline$v$ ring 5 & $1551 / 1530$ & 1556 & $1557 / 1552$ & -11 \\
\hline$v$ ring 6 & $1510 / 1498$ & 1497 & 1495 & -12 \\
\hline$\delta(\mathrm{C}-\mathrm{H})^{\prime} 1$ & 1411 & 1415 & $1416 / 1414$ & 6 \\
\hline$v(\mathrm{C}-\mathrm{N})$ & 1395 & 1400 & 1408 & 53 \\
\hline$\delta(\mathrm{C}-\mathrm{H})^{\prime \prime 2} 2$ & 1325 & 1324 & $1326 / 1317$ & -2 \\
\hline$v$ ring 2 & 1215 & 1221 & 1229 & -10 \\
\hline$\delta(\mathrm{C}-\mathrm{H})^{\prime} 2$ & not observed & not observed & not observed & \\
\hline$\delta$ ring 1 & 1121 & 1121 & 1130 & -4 \\
\hline$v$ ring 4 & 1085 & not observed & 1089 & -8 \\
\hline$\delta(\mathrm{C}-\mathrm{H})^{\prime \prime} 1$ & 1063 & 1065 & 1064 & -2 \\
\hline $\mathrm{w}\left(\mathrm{NH}_{2}\right)$ & 1148 & 1149 & 1151 & 88 \\
\hline$v$ ring 1 & 993 & 1002 & 1004 & 10 \\
\hline$\gamma(\mathrm{C}-\mathrm{H})^{\prime \prime 2} 2$ & not observed & not observed & 989 & -1 \\
\hline$\gamma(\mathrm{C}-\mathrm{H})^{\prime \prime} 1$ & 957 & 965 & $974 / 968$ & $10^{e}$ \\
\hline$\gamma(\mathrm{C}-\mathrm{H})^{\prime} 1$ & not observed & not observed & not observed & \\
\hline$\gamma(\mathrm{C}-\mathrm{H})^{\prime} 2$ & 853 & 853 & $856 / 853 / 851$ & 15 \\
\hline$\tau$ ring 1 & 756 & 757 & 763/761 & 12 \\
\hline$v(\mathrm{C}-\mathrm{C})$ & not observed & not observed & 753 & 5 \\
\hline$\gamma(\mathrm{C}=\mathrm{O})$ & 706 & 722 & $723 / 711$ & 14 \\
\hline$\delta$ ring 3 & 672 & 686 & $672 / 664$ & -12 \\
\hline$\delta(\mathrm{C}=\mathrm{O})$ & 628 & 623 & $632 / 629$ & 26 \\
\hline$\tau(\mathrm{C}-\mathrm{N})$ & 798/778 & $\sim 790$ & 829 & 286 \\
\hline$\delta(\mathrm{C}-\mathrm{C}-\mathrm{N})$ & $540 / 520$ & $\sim 500(?)$ & $\sim 500(?)$ & $0(?)$ \\
\hline $\begin{array}{l}\tau \text { ring } 3 \\
\tau \text { ring } 2\end{array}$ & \multirow{6}{*}{655} & \multirow{6}{*}{$\sim 650$} & \multirow{6}{*}{650} & \multirow{6}{*}{$316^{e}$} \\
\hline$\delta$ ring 2 & & & & \\
\hline$\gamma\left(\mathrm{NH}_{2}\right)$ & & & & \\
\hline $\mathrm{w}(\mathrm{C}-\mathrm{C})$ & & & & \\
\hline$\gamma(\mathrm{C}-\mathrm{C})$ & & & & \\
\hline$\tau(\mathrm{C}-\mathrm{C})$ & & & & \\
\hline
\end{tabular}

${ }^{a}$ Frequencies in $\mathrm{cm}^{-1}$; calculated intensities in $\mathrm{km} \mathrm{mol}^{-1} . \nu$, bond stretching; $\delta$, bending; $\gamma$, rocking; $\tau$, torsion; w, wagging; s, symmetric; as, asymmetric. ${ }^{b}$ The order of the modes in this table was chosen to be the same as that in Table 3 , for better comparison of the results obtained in the neat solid phases and for the matrix isolated molecule (and also with the calculated frequencies). ${ }^{c}$ The film with the glassy compound was first annealed to $280 \mathrm{~K}$ and then recooled to $10 \mathrm{~K} .{ }^{d}$ The frequency shifts were calculated using the average values of all bands assigned to a given mode, for features observed in both the crystalline state and in the matrix isolated compound. ${ }^{e}$ Calculated (scaled) frequency was used as reference value, in the absence of experimental data for the compound isolated in matrix.

the vibrations of $\mathrm{HNCO}$ are slightly different from those for the well-isolated compound (Table 6), clearly indicating that the large majority of the HNCO molecules resulting from the photolysis of PA cannot escape from the matrix cage where they are produced and are interacting with pyridine, which is formed together with HNCO (Figure 9). The extensive structure observed in the band ascribed to the $v \mathrm{NCO}$ vibrational mode in the $2300-2200 \mathrm{~cm}^{-1}$ region, otherwise a single broad band, ${ }^{49}$ is also in agreement with the involvement of $\mathrm{HNCO}$ in associates with pyridine.

Almost all bands expected for pyridine could be observed in the spectra of the PA-irradiated argon matrixes (Figure 8 and Table 6), confirming that this compound is produced together with $\mathrm{HNCO}$ in the photochemical reaction. Compared to that of the spectrum of the sole pyridine in argon matrix, ${ }^{51,52}$ the frequencies of the bands now observed in the photolyzed PA matrix spectra also appear slightly shifted due to the involvement of pyridine in associates with other photoproducts.

Very interestingly, the spectra of the photolyzed matrix also exhibit the characteristic band of carbon monoxide at ca. 2138 $\mathrm{cm}^{-1}$ (Figure 8), ${ }^{53}$ indicating that further processes took place upon irradiation of the matrix. In principle, there were two possible sources for the observed CO: (a) direct decarbonylation from PA, with simultaneous formation of 2-aminopyridine and (b) elimination of $\mathrm{CO}$ from isocyanic acid, leading also to the production of HN. Since no bands could be found in the spectra of the irradiated matrix that could be assigned to 2-aminopyridine (the IR spectrum of 2-aminopyridine was calculated at the B3LYP/G-311++G(d,p) level of theory and used to check for the presence of this compound in the irradiated matrix), the direct decarbonylation of PA could be doubtlessly discarded as source of the observed CO. Hence, CO must result from subsequent photoreactions of the initially formed isocyanic acid. Also in agreement with this interpretation the growing of the bands assigned to isocyanic acid practically stops upon prolonged irradiation of the matrix, indicating that this molecule should be involved in a secondary reaction.

The reactivity of isocyanic acid in low-temperature inert matrixes upon UV photolysis has been studied in detail since long ago, ${ }^{50,54-59}$ and two main primary reaction channels have 


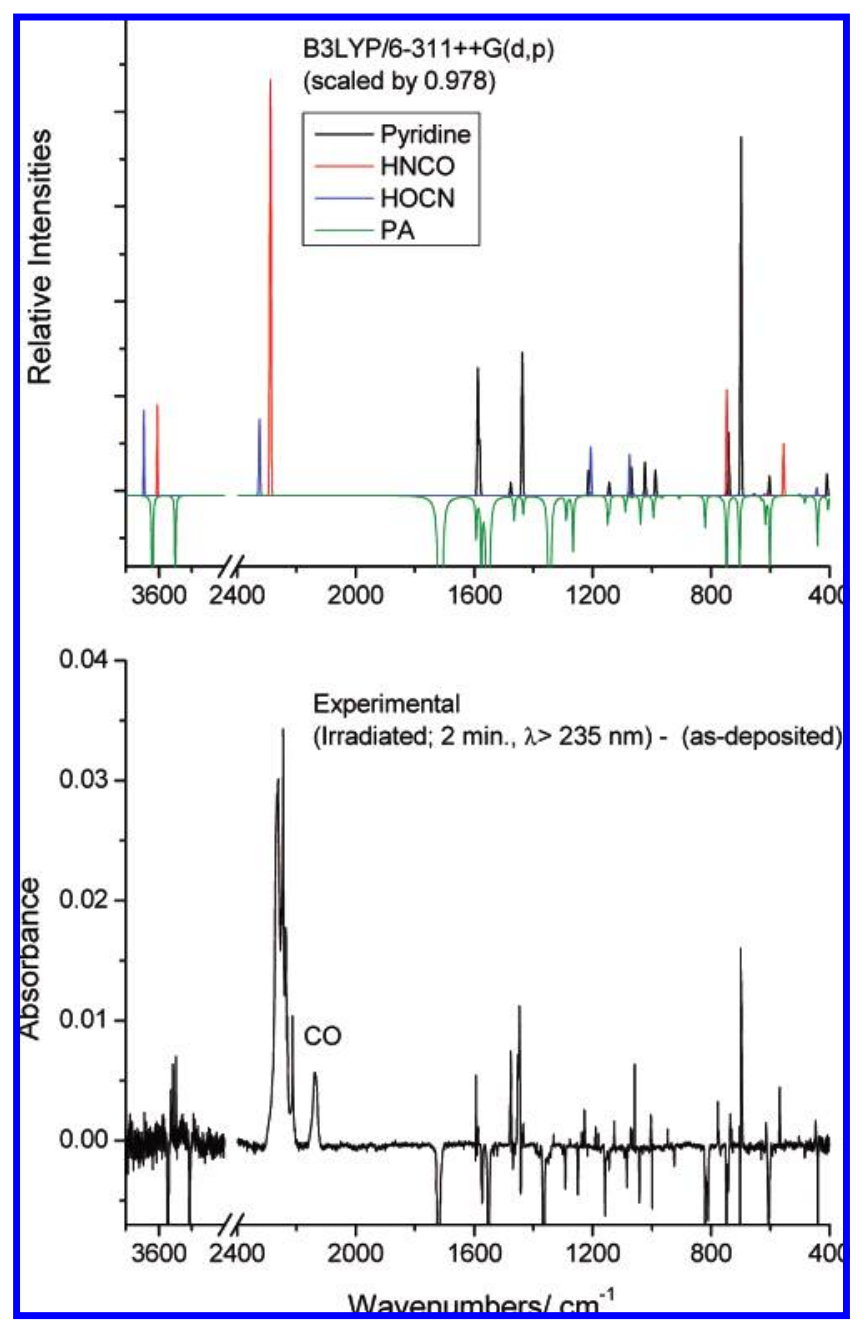

Figure 8. (Bottom) Infrared difference spectrum [(irradiated matrix by UV light; $\lambda>235 \mathrm{~nm} ; 2$ min) minus (as-deposited matrix spectrum)] of PA in an argon matrix. Assignments for the bands due to photoproducts (pointing up) are given in Table 4. The intensity of the spectrum of PA (pointing down) was reduced by a factor of $76 \%$. (Top) Simulation of the infrared difference spectrum shown in the bottom panel of the figure, based on the B3LYP/6-311++G(d,p) calculated spectra (wavenumbers scaled by 0.978 ) for PA (conformer I; bands pointing down) and for its photoproducts (pyridine, HNCO, and HOCN). The intensities of the individual spectra were multiplied by different factors to obtain a better simulation of the experimental difference spectra.

been proposed: (i) $\mathrm{HNCO} \rightarrow \mathrm{HN}+\mathrm{CO}$ and (ii) $\mathrm{HNCO} \rightarrow \mathrm{H}$ + NCO. Both channels allow for subsequent reactions to form cyanic acid (HOCN). In consonance with these results, a detailed examination of the spectra of the irradiated argon matrix of PA also revealed the presence of HOCN (Figure 8). This compound gives rise to the bands observed at 3573, 2280 (high frequency shoulder of the most intense band ascribed to the $v \mathrm{NCO}$ as stretching of isocyanic acid), 1228, 1072, 504, and $464 \mathrm{~cm}^{-1}$, which are in good agreement with both the theoretically obtained frequencies and previously reported vibrational data for HOCN isolated in argon matrix ${ }^{49}$ (Table 6).

Irradiation experiments undertaken using the same experimental procedures as those for PA were also carried out for INA. However, for this compound, even after prolonged irradiation (200 $\mathrm{min}$ ) of the matrixes (both argon and xenon), no photoreactions could be observed. It is quite interesting to note that an identical behavior was previously found for the analogous pyridinecarboxaldehydes. Indeed, very recently, Ohno et al. ${ }^{60}$ investigated the UV photolysis of matrix-isolated 2-,

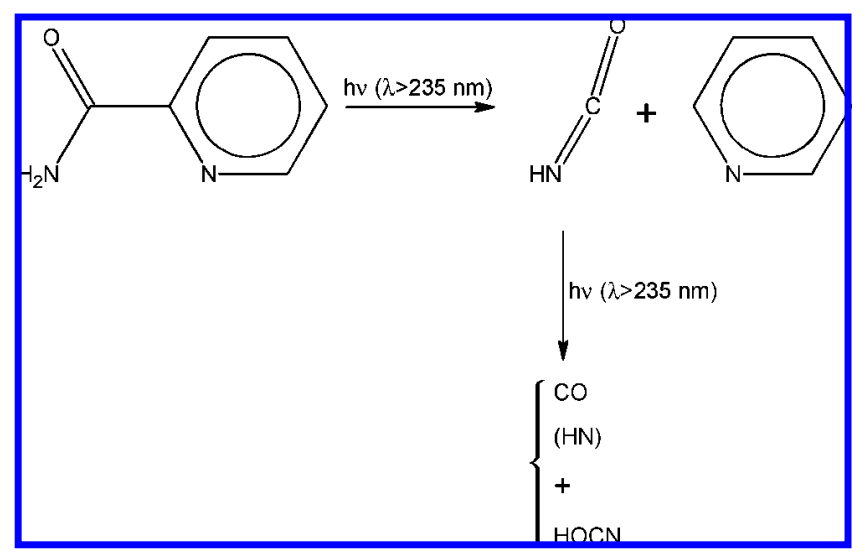

Figure 9. Proposed pathway resulting from in situ UV $(\lambda>235 \mathrm{~nm})$ irradiation of PA isolated in rare gas matrixes. All indicated photoproducts except HN could be experimentally observed.

3-, and 4-pyridinecarboxaldehyde, and they concluded that among the three isomers only the 2-substituted one undergoes UV photolysis, yielding $\mathrm{CO}+$ pyridine and reaction products.

Figure 10 shows the UV-visible spectra of PA and INA in water solution at room temperature. As shown, the spectra of the two compounds do not differ very much, in both cases indicating that in the irradiation experiments undertaken in this study for the matrix-isolated compounds excitation to the $S_{1}$ $\left(\pi, \pi^{*}\right)$ state has been carried out. Hence, only taking into consideration strict electronic characteristics of the two molecules it is difficult to explain its observed different reactivity upon photolysis. It seems clear that the presence of the nitrogen atom in a close proximity of one of the hydrogen atoms of the $\mathrm{NH}_{2}$ amide group in PA (or, in the case of the pyridinecarboxaldehydes, close to the aldehyde hydrogen atom in the most stable conformer of 2-pyridinecarboxaldehyde ${ }^{60}$ ) is essential to activate the molecule to photolytic transformations. In turn, this points to a mechanism where the cleavage of the $\mathrm{C}-\mathrm{C}$ bond occurs simultaneously with the $\mathrm{H}$-atom transfer from the substituent to the nitrogen ring, followed by fast 1,2-hydrogen shift from the nitrogen to the ortho carbon atom, most probably with pyridin-1-ium-2-ide as intermediate.

\section{Conclusions}

Picolinamide was shown to possess two different energy minima, but with only the most stable form presenting relevance in practical terms due to the considerably large energy difference between the two conformers $\left(>35 \mathrm{~kJ} \mathrm{~mol}^{-1}\right)$. Isonicotinamide was predicted to possess only one stable conformation. In consonance with the theoretical predictions, both PA and INA were found to exist in a single conformation in cryogenic rare gas matrixes. In argon matrix, PA was found to occupy two distinct matrix sites, which possess considerably different stabilities.

Full assignment of the spectra (in the $4000-400 \mathrm{~cm}^{-1}$ spectral range) of the matrix-isolated compounds was undertaken, supported by the results of the theoretical [B3LYP/6-311++G$(\mathrm{d}, \mathrm{p})]$ calculations. $\mathrm{UV}(\lambda>235 \mathrm{~nm})$ irradiation of the matrixes showed that while INA is nonreactive, PA undergoes easy photocleavage of the $\mathrm{C}_{(2)}-\mathrm{C}_{(11)}$, with production of isocyanic acid and pyridine, the first photoproduct further reacting to yield $\mathrm{CO}+\mathrm{NH}$ and cyanic acid. The different photochemical behavior of the two compounds was explained considering that in PA the ring nitrogen atom in the ortho position to the amide substituent facilitates the photochemical cleavage of the $\mathrm{C}-\mathrm{C}$ bond by accepting the amide $\mathrm{H}$-atom that is expelled from the 
TABLE 6: Assignment of the Bands of the Photoproducts Resulting from UV $(\lambda>235$ nm) Irradiation of PA in an Argon Matrix $^{a}$

\begin{tabular}{|c|c|c|c|c|}
\hline \multirow[b]{2}{*}{ approximate description } & \multicolumn{2}{|c|}{ calculated } & \multicolumn{2}{|c|}{ observed } \\
\hline & frequency & intensity & sole isolated species & photolyzed matrix (this study) \\
\hline \multirow[t]{2}{*}{$\mathrm{HNCO}$} & & & refs 49 and 50 & \\
\hline & & & $\int 3538$ & $\int 3530$ \\
\hline \multirow[t]{2}{*}{$v(\mathrm{~N}-\mathrm{H}) 1 \leftarrow 0$} & & & 3534 & 3527 \\
\hline & & & 3530 & 3525 \\
\hline \multirow{5}{*}{$v(\mathrm{~N}-\mathrm{H}) 0 \longleftarrow 0$} & & & $\{3517$ & $\{3514$ \\
\hline & 3609 & 170 & 3506 & 3496 \\
\hline & & & & 2266 \\
\hline & & & & 2261 \\
\hline & & & & 2250 \\
\hline \multirow[t]{4}{*}{$v(\mathrm{NCO})$ as. } & 2288 & 783 & 2259 & 2245 \\
\hline & & & & 2235 \\
\hline & & & & 2230 \\
\hline & & & & 2213 \\
\hline$\delta(\mathrm{HNC})$ & 747 & 199 & 770 & 777 \\
\hline$\delta(\mathrm{NCO})$ & 555 & 97 & 574 & 569 \\
\hline $\mathrm{HOCN}$ & & & refs 49 and 50 & \\
\hline$v(\mathrm{O}-\mathrm{H})$ & 3690 & 160 & 3570 & 3573 \\
\hline$v(\mathrm{C}-\mathrm{N})$ & 2325 & 143 & 2286 & 2280 \\
\hline$\delta(\mathrm{COH})$ & 1206 & 91 & 1228 & 1228 \\
\hline$v(\mathrm{C}-\mathrm{O})$ & 1075 & 77 & 1081 & 1072 \\
\hline$\delta(\mathrm{OCN})$ & 501 & 3 & n. obs. & $504(?)$ \\
\hline$\gamma(\mathrm{OCN})$ & 443 & 15 & n. obs. & 464 \\
\hline pyridine & & & refs 51 and 52 & \\
\hline$v$ ring & 1588 & 24 & 1584 & 1593 \\
\hline$v$ ring & 1582 & 10 & 1580 & 1587 \\
\hline$\delta(\mathrm{CH})[++0--]^{b}$ & 1477 & 2 & 1484 & 1476 \\
\hline$\delta(\mathrm{CH})[+---+]^{b}$ & 1438 & 27 & 1441 & 1452,1447 \\
\hline$\delta(\mathrm{CH})[+++++]^{b}$ & 1353 & $<1$ & n. obs. & $1331(?)$ \\
\hline$\delta(\mathrm{CH})[+-0+-]^{b}$ & 1214 & 5 & 1219 & 1221 \\
\hline$\delta(\mathrm{CH})[0+-+0]^{b}$ & 1144 & 2 & 1148 & 1128 \\
\hline$v(\mathrm{C}-\mathrm{N})$ as. & 1064 & 5 & 1073 & 1058 \\
\hline$\delta$ ring & 1023 & 6 & 1032 & 1034 \\
\hline$\tau$ ring & 998 & 5 & 992 & 1004 \\
\hline$\gamma(\mathrm{CH})[+0-0+]^{b}$ & 934 & $<1$ & n. obs. & 947(?) \\
\hline$\tau$ ring & 741 & 12 & 744 & 736 \\
\hline$\gamma(\mathrm{CH})[+++++]^{b}$ & 699 & 67 & 701 & 701 \\
\hline$v(\mathrm{C}-\mathrm{N}) \mathrm{s}$ & 603 & 4 & 602 & 616 \\
\hline
\end{tabular}

${ }^{a}$ Frequencies in $\mathrm{cm}^{-1}$, calculated intensities in $\mathrm{km} \mathrm{mol}^{-1} . \nu$, bond stretching, $\delta$, bending, $\gamma$, rocking, $\tau$, torsion, $\mathrm{s}$, symmetric, as, asymmetric, $\mathrm{n}$. obs., not observed. Calculated data were obtained at the B3LYP/6-311++G(d,p) and scaled by 0.978. ${ }^{b}$ Description of the vibration is given using "+" and "-" signs as indication of the direction of the movement of the $\mathrm{H}$ atoms; a " 0 " means that the atom does not move; the sequence of symbols starts in the $\mathrm{H}$ atom on carbon 2 and follows the usual atom numbering.

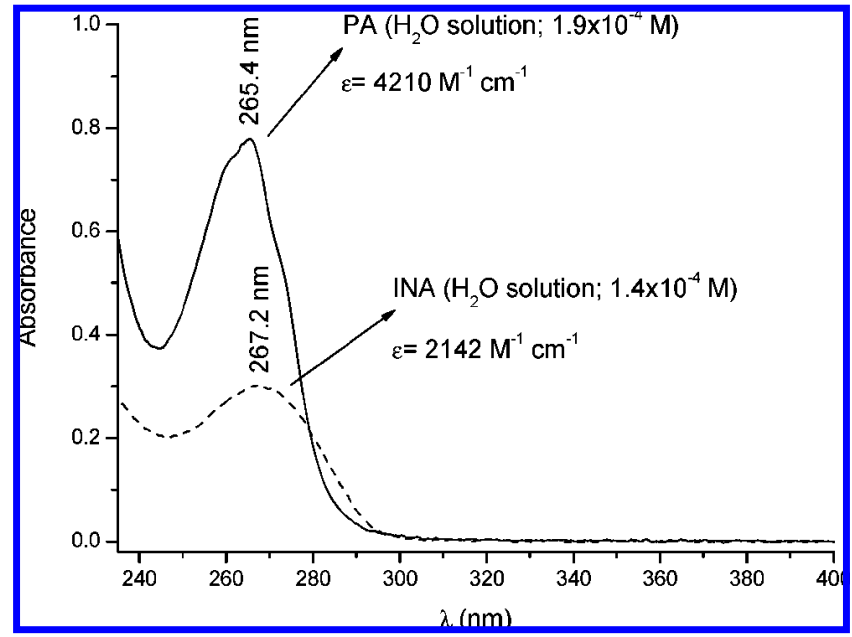

Figure 10. UV-visible spectra of PA and INA in water solutions.

amide group (to form isocyanic acid). Subsequent 1,2-migration of this hydrogen atom leads to formation of the observed final photoproduct: pyridine. The observed photochemical deami- dation of PA, now described for the first time, might have significance from the point of view of biological uses of the compound.

The infrared spectra of both the low-temperature glassy state and crystalline phase (resulting from the annealed glass) as well as those of the room-temperature crystal ( $\alpha$-phase) of the studied compounds were also investigated, and the relevant spectral parameters were correlated with intermolecular interactions present in the condensed phases, in particular H-bond interactions. These were found to be stronger in INA than those in PA.

Acknowledgment. This work was supported by FCT (Projects POCTI/QUI/59019/2004 and POCTI/QUI/58937/2004) and the Instituto de Investigação Interdisciplinar of the University of Coimbra (Project III/BIO/40/2005). A.B. acknowledges FCT for a Ph.D. grant (SFRH/BD/21543/2005). A.G.-Z. is a member of the Research Career of CONICET (National Research Council, Argentina).

Supporting Information Available: Additional tables. This material is available free of charge via the Internet at http:// pubs.acs.org. 


\section{References and Notes}

(1) Pero, R. W.; Olsson, A.; Amiri, A.; David, C. Cancer Detect. Prev 1998, 22, 225.

(2) Kawabata, T.; Ogino, T.; Mori, M.; Awai, M. Acta Pathol. Jpn. 1992, 42, 469 .

(3) Ogata, S.; Takeuchi, M.; Teradaira, S.; Yamamoto, N.; Iwata, K.; Okumura, K.; Taguchi, H. Biosci. Biotechnol. Biochem. 2002, 66, 641.

(4) Ogata, S.; Takeuchi, M.; Fujita, H.; Shibata, K.; Okumura, K.;

Taguchi, H. Biosci. Biotechnol. Biochem. 1998, 62, 2351.

(5) Shimai, T.; Islam, T.; Fukushi, Y.; Hashidoko, Y.; Yokosawa, R.; Tahara, S. Z. Naturforsch. 2002, 57, 323.

(6) Sarma, R. H.; Woronick, C. L. Biochemistry 1972, 11, 170

(7) Yamamoto, H.; Okamoto, H. Biochem. Biophys. Res. Commun

1980, 95, 474 41

(8) Yurdakul, S.; Ataç, A.; Sahin, E.; Íde, S. Vib. Spectrosc. 2003, 31,

(9) Singa, N. C.; Sathyanarayana, D. N. Spectrochim. Acta, Part A 1998, 54, 1059

(10) Anad, J.; Singha, N. C.; Sathyanarayana, D. N. J. Mol. Struct. 1997, $412,221$.

(11) Olsen, R. A.; Liu, L.; Ghaderi, N.; Johns, A.; Hatcher, M. E.; Mueller, L. J. J. Am. Chem. Soc. 2003, 125, 10125.

(12) Leskowitz, G. M.; Ghaderi, N.; Olsen, R. A.; Pederson, K.; Hatcher, M. E.; Mueller, L. J. J. Phys. Chem. A 2005, 109, 1152.

(13) Bakiler, M.; Bolukbasi, O.; Yilmaz, A. J. Mol. Struct. 2007, 826

(14) Filho, O. T.; Pinheiro, J. C.; Costa, E. B.; Kondo, R. T.; Souza, R. A.; Nogueira, V. M.; Mauro, A. E. THEOCHEM 2006, 763, 175. 744.

(15) Akalin, E.; Yilmaz, A.; Akyuz, S. J. Mol. Struct. 2005, 881,

(16) Takano, T.; Sasada, Y.; Kakudo, M. Acta Crystallogr. 1966, 21, 514.

(17) Aakeröy, C. B.; Beatty, A. M.; Helfrich, B. A.; Nieuwenhuyzen,

M. Cryst. Growth Des. 2003, 3, 159

(18) Akalin, E.; Akyuz, S. Vib. Spectrosc. 2006, 42, 333.

(19) Arenas, J. F.; Montañez, M. A.; Otero, J. C.; Marcos, J. I. J. Mol. Struct. 1993, 293, 341.

(20) Pal, T.; Narayanan, V. A.; Stokes, D. L.; Vo-Dinh, T. Anal. Chim. Acta 1998, 368, 21.

(21) National Institute of Standards and Technology. 2-Pyridinecarboxamide. http://webbook.nist.gov/cgi/cbook.cgi?ID=1452773\&Units= SI\&Type $=$ IR-SPEC\&Index $=0 \# I R-S P E C /$.

(22) Girling, D. J. Drugs 1982, 23, 56.

(23) Vargas, F.; Rivas, C.; Díaz, Y.; Fuentes, A. J. Photochem. Photobiol., B 2003, 72, 87 .

(24) Givens, R. S.; Levi, N. In The Chemistry of Acid Derivatives; Patai, S., Ed.; The Chemistry of Functional Groups, Supplement B; Wiley: London, 1979; pp 640-653.

(25) Naik, P. D.; Upadhyaya, H. P.; Kumar, A.; Sapre, A. V.; Mittal, J. P. J. Photochem. Photobiol., C 2003, 3, 165

(26) Frisch, M. J. T.; Trucks, G. W.; Schlegel, H. B.; Scuseria, G. E.; Robb, M. A.; Cheeseman, J. R.; Zakrzewski, V. G.; Montgomery, J. A.; Stratmann, R. E.; Burant, J. C.; Dapprich, S.; Millam, J. M.; Daniels, A D.; Kudin, K. N.; Strain, M. C.; Farkas, O.; Tomasi, J.; Barone, V.; Cossi, M.; Cammi, M.; Mennucci, B.; Pomelli, C.; Adamo, C.; Clifford, S.; Ochterski, J.; Petersson, G. A.; Ayala, P. Y.; Cui, Q.; Morokuma, K.; Malick, D. K.; Rabuck, A. D.; Raghavachari, K.; Foresman, J. B.; Cioslowski, J.; Ortiz, J. V.; Baboul, A. G.; Stefanov, B. B.; Liu, G.; Liashenko, A.; Piskorz, P.; Komaromi, I.; Gomperts, R.; Martin, R. L.; Fox, D. J.; Keith, T.; AlLaham, M. A.; Peng, C. Y.; Nanayakkara, A.; Challacombe, M.; Gill, P. M.; Johnson, B. G.; Chen, W.; Wong, M. W.; Andres, J. L.; Gonzalez, C.;
Head-Gordon, M.; Replogle, E. S.; Pople, J. A. Gaussian 98, revision A.9; Gaussian Inc.: Pittsburgh, PA, 1998.

(27) Frisch, M.; Head-Gordon, M.; Pople, J. Chem. Phys. Lett. 1990, $166,281$.

(28) Becke, A. Phys. Rev. A 1988, 38, 3098

(29) Lee, C.; Yang, W.; Parr, R. Phys. Rev. B 1988, 37, 785.

(30) Vosko, S.; Wilk, L.; Nusair, M. Can. J. Phvs. 1980, 58, 1200.

(31) Csaszar, P.; Pulay, P. J. Mol. Struct.: THEOCHEM 1984, 114 ,

(32) Schachtschneider, J. Technical Report; Shell Development Co.: Emeryville, CA, 1969.

(33) Peng, C.; Schlegel, H. Isr. J. Chem. 1994, 33, 449.

(34) Reva, I. D.; Ilieva, S. V.; Fausto, R. Phys. Chem. Chem. Phys. 2001, 3, 4235.

(35) Reva, I. D.; Stepanian, S. G.; Adamowicz, L.; Fausto, R. Chem. Phys. Lett. 2003, 374, 631 .

(36) Kaczor, A.; Reva, I. D.; Proniewicz, L. M.; Fausto, R. J. Phys. Chem. A 2006, 110, 2360.

(37) Jarmelo, S.; Lapinski, L.; Nowak, M. J.; Carey, P. R.; Fausto, R. J. Phys. Chem. A 2005, 109, 5689.

(38) Jarmelo, S.; Reva, I. D.; Carey, P. R.; Fausto, R. Vib. Spectrosc 2007, 43, 104

(39) Jarmelo, S.; Reva, I.; Rozenberg, M.; Fausto, R. Vib. Spectrosc 2006, 41,73 .

(40) Rozenberg, M.; Shoham, G.; Reva, I. D.; Fausto, R. Phys. Chem. Chem. Phvs. 2005, 7, 2376.

(41) Lopes, S.; Gómez-Zavaglia, A.; Lapinski, L.; Fausto, R. J. Phvs. Chem. A 2005, 109, 5560.

(42) Rozenberg, M.; Shoham, G.; Reva, I.; Fausto, R. Spectrochim. Acta Part A 2005, 62, 233

(43) Jarmelo, S.; Maiti, N.; Anderson, V.; Carey, P. R.; Fausto, R. J. Phys. Chem. A 2005, 109, 2069.

(44) Rozenberg, M.; Shoham, G.; Reva, I. D.; Fausto, R. Spectrochim Acta, Part A 2004, 60, 2319.

(45) Gómez-Zavaglia A.; Fausto, R. Phys. Chem. Chem. Phys. 2003, 5 3154.

(46) Rozenberg, M.; Shoham, G.; Reva, I. D.; Fausto, R. Spectrochim Acta, Part A 2003, 60, 463.

(47) Rozenberg, M.; Shoham, G.; Reva, I. D.; Fausto, R. Spectrochim. Acta, Part A 2003, 59, 3253

(48) Bugalho, S. C. S.; Lapinski, L.; Cristiano, M. L. S.; Frija, L. M. T.; Fausto, R. Vib. Spectrosc. 2002, 30, 213.

(49) Teles, J. H.; Maier, G.; Hess, B. A.; Schaad, L. J., Jr.; Winnewisser,

M.; Winnewisser, B. P. Chem. Ber. 1989, 122, 753.

(50) Jacox, M. E.; Milligan, D. E. J. Chem. Phys. 1964, 40, 2457

(51) Kudoh, S.; Takayanagi, M.; Nakata, M. J. Photochem. Photobiol.

A 1999, 123, 25.

(52) Johnstone, D. E.; Sodeau, J. R. J. Phys. Chem. 1991, 95, 165.

(53) Dubost, H.; Abouaf-Marguin, L.; Legay, F. Phys. Rev. Lett. 1972 29,145 .

(54) Fischer, G.; Geith, J.; Klapötke, T. M.; Krumm, B. Z. Naturforsch 2002, 57B, 19.

(55) Okabe, H. J. Chem. Phys. 1970, 53, 3507.

(56) Bondybey, V. E.; English, J. H.; Mathews, C. W.; Contolini, R. J. I. Mol. Spectrosc. 1982, 92, 431.

(57) Milligan D. E.; Jacox, M. E. J. Chem. Phys. 1967, 47, 5157

(58) Pettersson, M.; Khriachtchev, L.; Jolkkonen, S.; Räsänen, M. J. Phvs. Chem. A 1999, 103, 9154.

(59) Pettersson, M.; Khriachtchev, L.; Lundell, J.; Jolkkonen, S.; Räsänen, M. J. Phys. Chem. A 2000, 104, 3579.

(60) Ohno, K.; Itoh, T.; Yokota, C.; Katsumoto, Y. J. Mol. Struct. 2006, 825,143 . 